Research Article

\title{
Modeling and Dynamics Analysis of a Dual-Mass Flywheel with the Conformal Contact Action of Friction Damping Ring and Pressure Plate
}

\author{
Liping Zeng $\mathbb{D}^{1},{ }^{1}$ Jie Huang, ${ }^{1}$ Yukun $X{ }^{1},{ }^{1}$ and Liquan Song ${ }^{2}$ \\ ${ }^{1}$ Key Laboratory of Conveyance and Equipment Ministry of Education, School of Mechatronics and Vehicle Engineering, \\ East China Jiaotong University, Nanchang 330013, China \\ ${ }^{2}$ College of Mechanical Engineering, Chongqing University, Chongqing 400044, China
}

Correspondence should be addressed to Liping Zeng; melpzeng@163.com

Received 20 July 2021; Accepted 3 December 2021; Published 16 December 2021

Academic Editor: Gerardo Silva-Navarro

Copyright (C) 2021 Liping Zeng et al. This is an open access article distributed under the Creative Commons Attribution License, which permits unrestricted use, distribution, and reproduction in any medium, provided the original work is properly cited.

To study the nonlinear dynamic characteristics of the dual-mass flywheel (DMF) under the conformal contact action between the friction damping ring and primary flywheel pressure plate, the contact action model is established and analyzed based on Winkler model. Through analysis and calculation, the contact deformation, contact pressure at different contact positions, and equivalent torsional contact stiffness are obtained. The nonlinear dynamic analysis model of three-degree-of-freedom (3DOF) which takes the conformal contact into account and two-degree-of-freedom (2DOF) without considering conformal contact is established. The approximate analytical solution of the nonlinear frequency characteristics of the system at steady state is derived. By comparing with the results obtained from numerical method, the theoretical analysis process is proved to be valid. And it is found that the overall amplitude and angular displacement transmissibility of the 3DOF model are smaller than the 2DOF model, especially at resonance frequency. The effects of the friction damping ring moment inertia, stiffness of DMF, and axial friction torque on the frequency characteristics of system and angular displacement transmissibility are analyzed. The forced vibration response analysis of the 3DOF model is conducted, through which the torsional angle variations of the primary flywheel, friction damping ring, and secondary flywheel with time are obtained. The results show that the amplitude of the secondary flywheel is much smaller than that of the primary flywheel, indicating that the DMF has prominent damping performance.

\section{Introduction}

Dual-mass flywheel (DMF), which was first proposed by companies represented by LuK, can efficiently reduce the torsional vibration and noise, relieve impact, realize the protection of engine and gearbox against overload, and enable the engine to operate at lower speeds to reduce fuel consumption [1-4]. Generally speaking, through reasonable parameter matching, DMF can make the natural frequency of the automobile transmission system isolated outside the frequency corresponding to the normal speed range of the engine [5]. Owing to these significant advantages, now DMF is wildly applied in automotive transmission system $[6,7]$, and there are many academic researches on the DMF. Berbyuk [8] studied the feasibility of the application of a
DMF for heavy-duty truck drivetrain system. And the optimized mass inertia, stiffness, and damping parameters of a DMF were proved to provide the better attenuation of the torque oscillations. To make a DMF with three-stage stiffness have continuous variable stiffness, Song et al. [9] proposed a new structure improvement by using shape constraints and compensation principle. References $[2,10]$ focused on the measure method of the DMF angular displacement. Tang et al. [11] investigated the effect of a DMF on the torsional vibration characteristics of a power-split hybrid powertrain system. Theodossiades et al. [4] investigated the effect of DMF on impact-induced clonk noise and its severity through experimentation. Chen et al. [12] analyzed the dynamic torsional characteristics of a circumferential arc spring DMF from theoretical study and experiments. And it 
was found that the torsional stiffness of the DMF varies with the excitation amplitude and frequency. Güllü et al. [13] proved that DMF can make the clutching process perform more smoothly than single-mass flywheel. Li et al. [14] proposed a radial spring DMF with good nonlinear torsional stiffness characteristics owing to the moment inertia of the torsional vibration damper allocated reasonably and the torsional stiffness of the torsional vibration spring designed properly. Mao et al. [15] and $\mathrm{Zu}$ et al. [16] established the simulation model of magnetorheological DMF in Amesim software and analyzed the attenuation of torsional vibration of transmission system under various working conditions. Chen et al. [17] built the multidegree powertrain torsional vibration model which contains magnetorheological fluid DMF and semiactive fuzzy control model and researched the torsional vibration damping characteristic of the DMF and the control system in vehicle powertrain system.

To meet the requirements of small torsional angle and stiffness at low speed and low torque, and large stiffness and output torque at high speed and high input torque, DMFs generally possess nonlinear stiffness characteristics, i.e., its stiffness will change with the relative angular displacement of the primary flywheel and the secondary flywheel. Song et al. [18] proposed the design theory of a two-stage piecewise variable stiffness DMF, and the torque characteristics and frequency characteristics are analyzed by theoretical study and experiments. Wang et al. [19] investigate the kinetic parameters matching and designing method for a multistage torsional stiffness DMF based on torsional vibration control by using the numerical analysis methods and proved by tests on an actual vehicle. Shi et al. [20] proposed an innovative arrangement of elastic structure applied in DMF to make this vibration damper have multipiece step stiffness and conducted the natural characteristic analysis of the transmission system at driving and idling conditions to evaluate this DMF vibration control effects. For the DMF matching under start-up condition, He et al. [21] investigated the influence of a five-stage variable stiffness DMF kinetic parameter on driveline torsional vibration in engine start-up process.

In Ref [18], a friction damping ring structure is introduced into DMF to further reduce torsional vibration based on the equivalent damping effect of the axial friction torque produced by axial preload. According to the DMF structure, high conformal contact is formed between the introduced friction damping ring and the primary flywheel pressure plate. Usually, contact problem is a complex process involving elastic deformation and other factors, and usually, multibody system dynamics problems involving contact have nonlinear characteristics [22]. The existing literature has carried out a lot of research on the structure of the DMF, torsional characteristics, and vibration damping performance. But few studies consider the influence of inner part contact on the dynamic characteristics of DMF in the previous works.

The present work is devoted to study the nonlinear dynamic characteristics of DMF with considering the conformal contact action between the friction damping ring and the primary flywheel pressure plate. Through establishing the contact analysis model based on Winkler model, the contact deformation and contact pressure at different contact positions, and the equivalent torsional contact stiffness generated by the conformal contact can be obtained. Then, the nonlinear dynamic analysis model of the DMF is established, and the approximate analytical solution of the nonlinear frequency characteristics of the system at steady state is solved by using averaging method. To verify the validity of the solution process, the results are compared with the system steady-state response amplitude obtained by applying the fourth-order Runge-Kutta numerical method with fixed step. The steady-state frequency characteristics and angular displacement transmissibility of the three-degree-of-freedom (3DOF) model which takes conformal contact into account are compared with the two-degree-offreedom (2DOF) model without considering conformal contact. The effects of moment inertia ratio, DMF stiffness, and axial friction torque on the frequency characteristics of system dynamic response and angular displacement transmissibility are demonstrated.

\section{DMF Structure}

Figure 1 shows the schematic diagram of the DMF structure, which is mainly composed of six parts. The spring 3 used for vibration reduction is fixed between the two flanges of the primary flywheel 1 through two spring seats 2 , and the friction damping ring 5 is placed between the primary flywheel pressure plate 6 and the secondary flywheel 4 . In the working process of the DMF, the primary flywheel connected with the engine crankshaft is driven to rotate. The primary flywheel compresses the damping springs installed between the flanges, and the spring seats move the secondary flywheel. In addition, the axial friction torque between the primary flywheel and the secondary flywheel is generated by the preload applied in the axial direction of the friction damping ring.

\section{Conformal Contact Action of the Friction Damping Ring and Pressure Plate}

3.1. Winkler Model. Contact between parts in multibody system is a common phenomenon. The analysis and solution of the contact problems generally involve many factors such as friction theory, dynamics, elastic deformation, and calculation method. And now it has been a topic of interest to researchers. As illustrated by Corral in [23], now there are many contact models, such as Hertz model, Hooke's model, and Kelvin-Voigt model, but they generally have specific applicable characteristics. The Winkler model can be well applied to the contact pressure calculation of high conformal contact problems and wear simulation, which can avoid the complexity of contact pressure calculation [24, 25]. For example, Su et al. [26] used Winkler model to calculate joint reaction and contact pressure, and the result shows that the contact pressure calculated by this model has a better accuracy than the result computed by Hertz contact theory. Mukras et al. [27] found that Winkler contact model can consider the influence of the shape and size of the hinge joint 


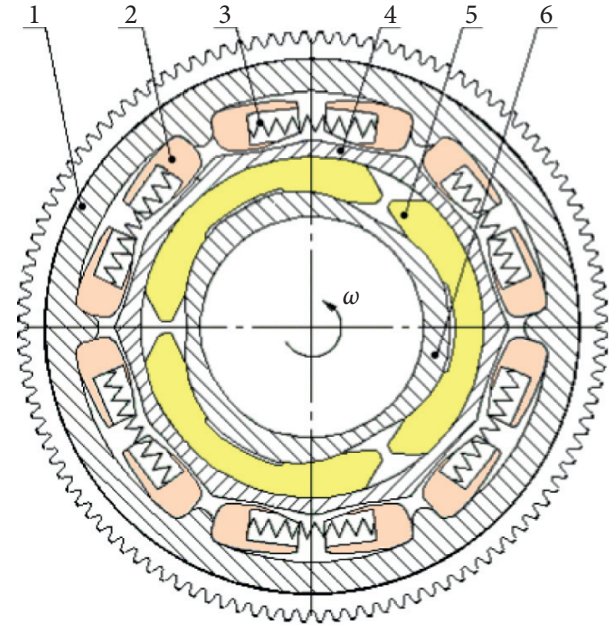

FIGURE 1: Structural diagram of the DMF: 1: primary flywheel; 2 : spring seat; 3: spring; 4: secondary flywheel; 5 : friction damping ring; 6: primary flywheel pressure plate.

better than other models when analyzing the wear of hinged joints with clearance. Zhu et al. [25] proposed a NLCP model with considering the nonlinear relationship between contact force and contact deformation based on Winkler contact model when analyzing the wear of hinged joints with clearance.

The Winkler model ignores the shearing action on the contact surface, and the contact interface is modeled as a series of springs. As shown in Figure 2, the relationship between contact pressure and contact deformation (penetration depth) is described as follows:

$$
p=E^{*} \frac{\delta}{L},
$$

where $E^{*}$ is the synthesis elastic modulus of the two contacting objects, $\delta$ is the deformation, and $L$ is the length before deformation.

3.2. Contact Deformation. Figure 3(a) shows the initial state before the deformation; the primary flywheel pressure plate 6 and the friction damping ring 5 , and the friction damping ring 5 and the secondary flywheel 4 are face-to-face contacts. We establish a rectangular coordinate system $O x y$ with the rotation center $O$ of the DMF as the origin point. The contact surface of the pressure plate and the friction damping ring is an arc with $O_{1}$ as the center, and the eccentric distance $l_{\mathrm{OO} 1}=e$. The contact surface of the friction damping ring and the secondary flywheel is an arc with $O$ point as the center, and the interaction between the two can be approximated as no deformation.

It is assumed that point $C$ is a contact point on the contact surface between the friction damping ring and the primary flywheel pressure plate when the DMF works as shown in Figure $3(\mathrm{~b})$. Under torque action, the angular displacement of the pressure plate relative to the friction damping ring is $\theta$, and the interaction line between the pressure plate and the friction damping ring moves to the arc with $O_{2}$ as the center (solid line II) from the arc with $O_{1}$ as the center (dotted line I). At this time, the elastic deformation of the point $C$ at the angle of $\alpha$ with the $y$-axis is $l_{C D}=\delta_{\alpha}$.

The arc I takes $O_{1}$ as the center of the circle, and the coordinates before the deformation of the contact point $C$ are $(r \sin \alpha, e+r \cos \alpha)$. The equation of the straight line $O_{1} C$ is $y=x \cot \alpha+e$. Thus, the equations of arc I and II are as follows:

$$
\left\{\begin{array}{l}
\text { I: } x^{2}+(y-e)^{2}=r^{2}, \\
\text { II: }(x-e \sin \theta)^{2}+(y-e \cos \theta)^{2}=r^{2} .
\end{array}\right.
$$

The coordinates of point $D$ can be obtained by substituting the equation of line $O_{1} C$ into the equation of arc II. Then, the length of $C D$ is obtained:

$$
\begin{aligned}
\delta_{\alpha}= & \sqrt{r^{2}-e^{2}(\sin (\alpha-\theta)-\sin \alpha)^{2}} \\
& +e(\cos (\alpha-\theta)-\cos \alpha)-r .
\end{aligned}
$$

In order to simplify the analysis and calculation, equation (3) is regarded as a function of the independent variable $\alpha$, and the first three terms are expanded by Taylor series at $\alpha=0$ for approximate calculation:

$$
\delta_{\alpha} \approx \theta e \sin \alpha-\frac{\theta^{2}}{2} e\left(\cos \alpha+\frac{e}{r}\right) \approx \theta e \sin \alpha .
$$

For the actual structure, in equations (3) and (4), $e=16 \mathrm{~mm}, r=60 \mathrm{~mm}$. When $\theta=1^{\circ}$ and the angle of contact area $\alpha_{\max }$ is $50^{\circ}$, the approximate deformation and the actual deformation are shown in Figure 4. The small difference between the approximate deformation and the actual deformation indicates that this approximate equivalence is reasonable.

The outer arc equation of the friction damping ring is as follows: $x^{2}+y^{2}=R^{2}$. $H$ is the intersection point of line $O_{1} C$ and the outer circular arc of the friction damping ring. The length of $O_{1} H$ can be calculated and expressed as

$$
l_{O_{1} H}=\frac{x_{H}}{\sin \alpha}=\sqrt{R^{2}-e^{2} \sin ^{2} \alpha}-e \cos \alpha .
$$

Normal thickness of the friction damping ring at point $C$ before deformation is as follows:

$$
\begin{aligned}
L_{\alpha} & =l_{C H} \\
& =l_{O_{1} H}-r \\
& =\sqrt{R^{2}-e^{2} \sin ^{2} \alpha}-(r+e \cos \alpha) .
\end{aligned}
$$

\subsection{Torque Generated by Conformal Contact Action. As} shown in Figure 5(a), suppose the contact pressure at point $D$ on the contact surface is $p_{\alpha}$ and the unit contact area is $A$, the contact force $F_{\alpha}$ at the contact point can be expressed as

$$
F_{\alpha}=p_{\alpha} A=E^{*} \frac{\delta_{\alpha}}{L_{\alpha}} r h d \alpha,
$$

where $d \alpha$ is a small arc degree and $h$ is axial contact length.

The torque generated by force $F_{\alpha}$ is as follows: 


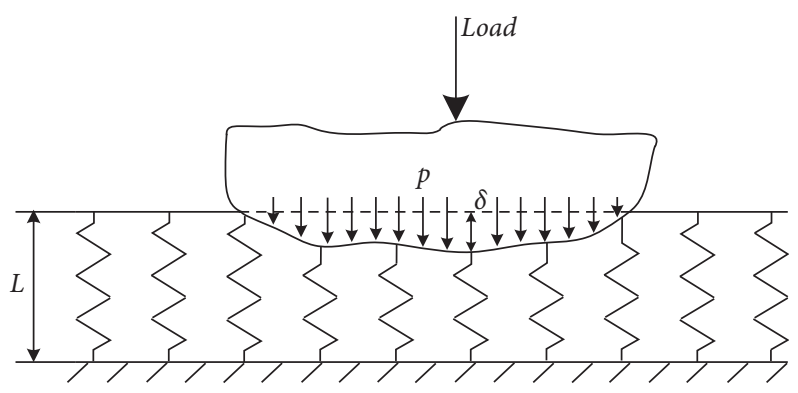

Figure 2: Winkler model.

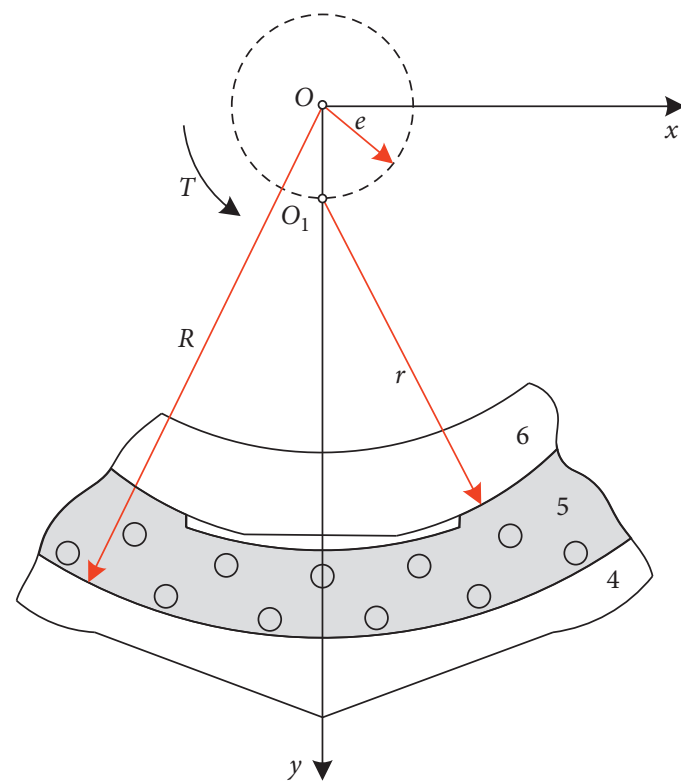

(a)

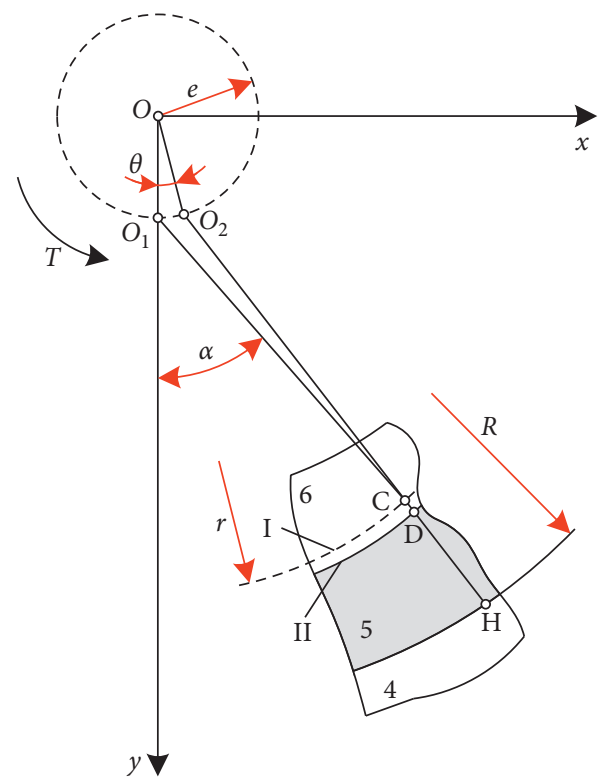

(b)

FIgURE 3: Contact deformation of the friction damping ring. (a) Initial state. (b) Contact deformation after a relative angle $\theta$.

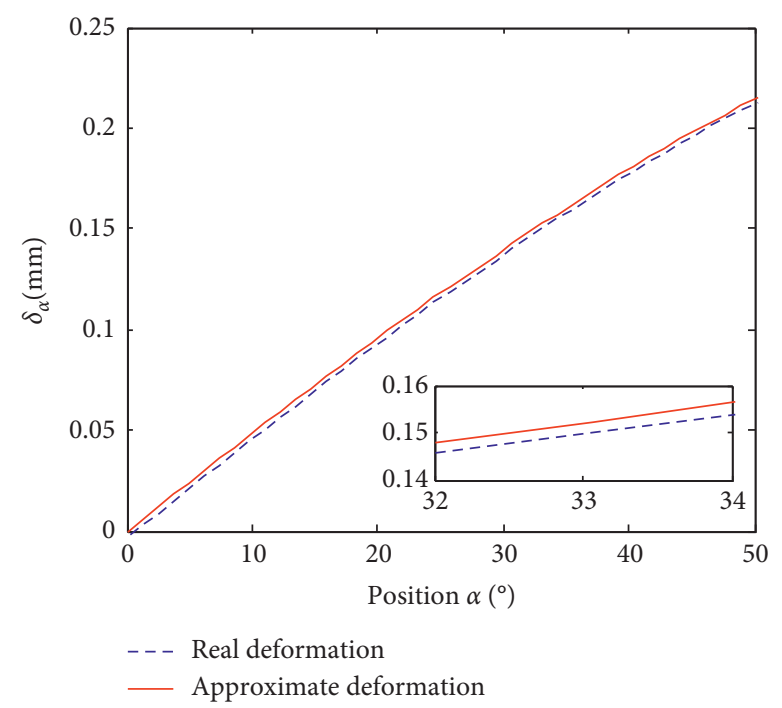

Figure 4: Contact deformation at different positions. 


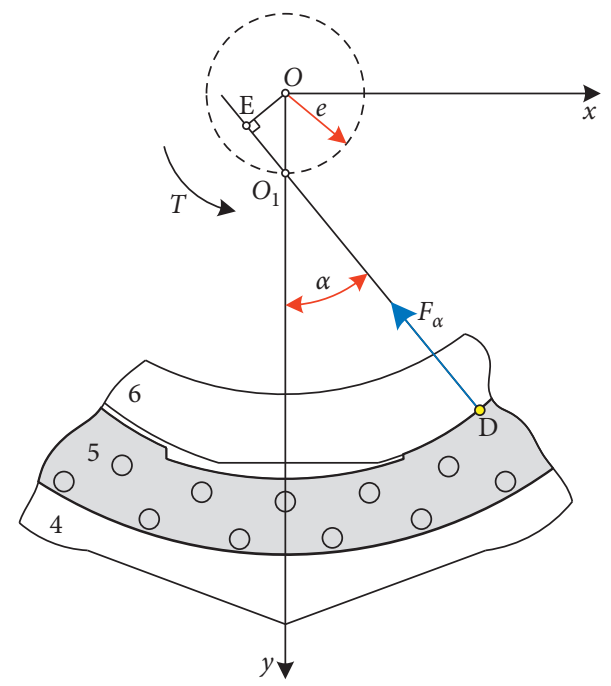

(a)

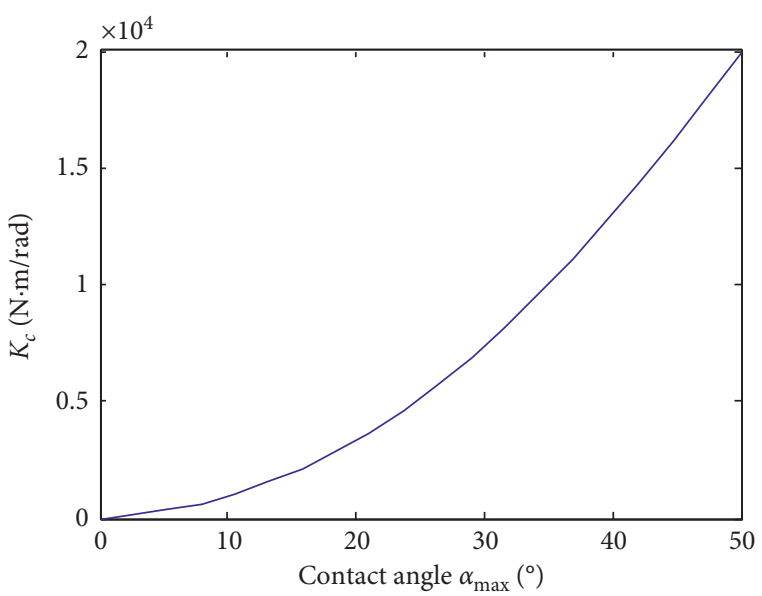

(b)

Figure 5: Contact force analysis. (a) Contact force. (b) Contact stiffness with different contact angle $\alpha_{\max }$.

$$
T_{\alpha}=F_{\alpha} l_{O E}=F_{\alpha} e \sin \alpha .
$$

According to equations (1)-(4) and (6)-(8), the total torque produced by the contact action of the friction damping ring and the primary flywheel pressure plate can be obtained:

$$
T_{d}=\int T_{\alpha}=K_{c} \theta
$$

where $K_{c}$ is the conformal contact stiffness between the friction damping ring and the primary flywheel pressure plate, and it is expressed as

$$
K_{c}=E^{*} r h e^{2} \int \frac{\sin ^{2} \alpha}{\sqrt{R^{2}-e^{2} \sin ^{2} \alpha}-(r+e \cos \alpha)} \mathrm{d} \alpha .
$$

The relationship between the contact stiffness and the angle of the contact region $\alpha_{\max }$ is shown in Figure 5(b). It can be seen that $K_{c}$ increases nonlinearly with the increase of the contact angle $\alpha_{\max }$, and $K_{c}$ is about $20000 \mathrm{~N} \cdot \mathrm{m} / \mathrm{rad}$ when $\alpha_{\max }=50^{\circ}$.

\section{Dynamic Analysis Model of DMF}

4.1. Dynamic Model. For the cyclical change of the engine cylinder pressure and the inertial force generated by the reciprocating motion of the crank link mechanism in internal combustion engines, the output torque from the engine changes continuously, which can be generally expressed as $[19,28]$ :

$$
T_{e}=T_{0}+\sum_{\gamma=0.5}^{\infty} T_{\gamma} \sin \left(\gamma \omega t+\psi_{r}\right),
$$

where $T_{0}$ is the average torque caused by cylinder pressure in a cycle, $\gamma$ represents the harmonic number, $\gamma=1 / 2,1,3 / 2,2$, $\ldots, T_{\gamma}$ is the amplitude of torque at harmonic number $\gamma, \omega$ is the angular velocity of crankshaft, and $\psi_{\gamma}$ is the initial phase at harmonic number $\gamma$. Assume the external excitation on the primary flywheel is in a harmonic change form: $T_{e}=T_{p} \sin \omega t$.

Compared with the DMF, the moment inertia of vehicle subsystem behind clutch-driven plate and wheel is very large. Therefore, the wheel and vehicle subsystem is assumed to be rigid $[29,30]$. As shown in Figure 6(a), 3DOF torsional vibration analysis model is established to study the DMF dynamic characteristics according to vehicle powertrain system, where $\theta_{1}$ is the angular displacement of the primary flywheel, $\theta_{2}$ is the angular displacement of the friction damping ring, $\theta_{3}$ is the angular displacement of the secondary flywheel, $J_{1}$ is the equivalent moment inertia of the primary flywheel and its front parts, $J_{2}$ is the moment inertia of the friction damping ring around the rotation center $O, J_{3}$ is the equivalent moment inertia of the secondary flywheel and clutch-driven plate, $c_{s}$ is the damping between the primary flywheel and the secondary flywheel, $k_{g}$ and $c_{g}$ are the equivalent stiffness and damping associated with the automotive driveline, $T_{s}$ is the torque acting through the springs between the primary flywheel and the secondary flywheel, $T_{d}\left(\theta_{1}, \theta_{2}\right)$ is the contact torque of the friction damping ring and the primary flywheel pressure plate, and $M_{f}$ is the axial friction torque between the single friction damping ring (there are three uniformly arranged friction damping rings in total) and second flywheel, which is produced by the axial preload. In addition, the 2DOF model shown in Figure 6(b) is also established without considering the contact influence between the friction damping ring and the primary flywheel pressure plate.

As shown in Figure 6(c), the stiffness of the DMF is divided into two stages: $k_{1}$ at small angular displacements and $k_{2}$ at large angular displacements, namely

$$
k= \begin{cases}k_{1}, & \text { if }-\beta \leq \theta \leq \beta, \\ k_{2}, & \text { else }\end{cases}
$$

where $\theta=\theta_{1}-\theta_{3}, \beta$ is the relative angular displacement when the stiffness begins to change. 


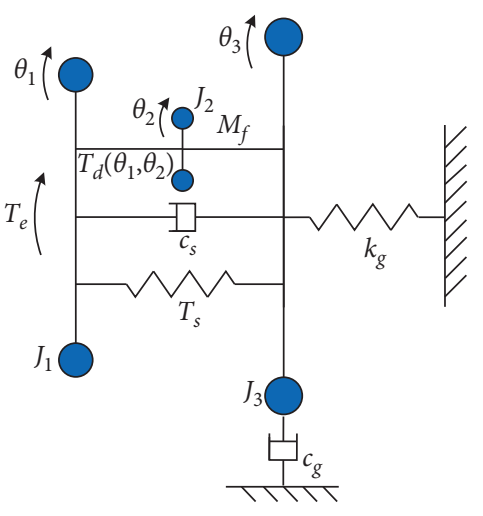

(a)

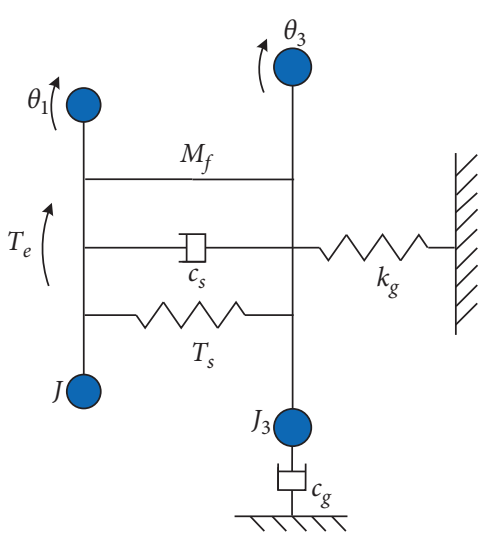

(b)

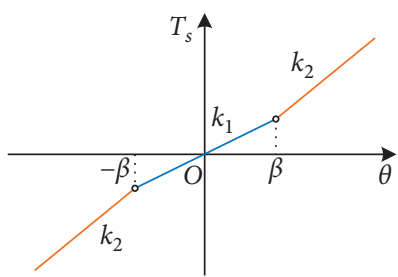

(c)

FIgure 6: DMF analysis model. (a) 3DOF model. (b) 2DOF model. (c) Piecewise variable stiffness of the damping spring.

Then, the torque $T_{\mathrm{s}}$ produced by the damping springs between the primary flywheel and the secondary flywheel is expressed as

$$
T_{s}= \begin{cases}k_{1} \theta, & \text { if }-\beta \leq \theta \leq \beta, \\ k_{2}(\theta-\beta)+k_{1} \beta, & \text { if } \theta>\beta, \\ k_{2}(\theta+\beta)-k_{1} \beta, & \text { else. }\end{cases}
$$

Suppose $\theta$ has the form $\theta=A \cos \Theta$ under the engine sinusoidal torque excitation, where $A$ is amplitude, $\Theta=\omega t+\psi, \psi$ is the phase angle.

When $A \geq \beta, T_{s}$ is expanded by Fourier series as

$$
T_{s}=\left(\begin{array}{c}
\left(k_{1}+\frac{1}{\pi}\left(k_{2}-k_{1}\right)\left(2 \varphi_{0}-\sin 2 \varphi_{0}\right)\right) \cos \Theta+\frac{1}{\pi}\left(k_{2}-k_{1}\right) \times \\
\sum_{m=1}^{\infty}\left(\frac{1}{m} \sin 2 m \Theta_{0}-\frac{1}{m+1} \sin (2 m+2) \Theta_{0}\right) \frac{\cos (2 m+1) \Theta}{2 m+1}
\end{array}\right) A,
$$

where $\Theta_{0}=\arccos \beta / A$.

Let $T_{s}=\left(k_{1}+1 / \pi\left(k_{2}-k_{1}\right)\left(2 \Theta_{0}-\sin 2 \Theta_{0}\right)\right) A \cos \Theta \quad$ trated as and $k_{e}=k_{1}+1 / \pi\left(k_{2}-k_{1}\right)\left(2 \Theta_{0}-\sin 2 \Theta_{0}\right)$.

$$
\left\{\begin{array}{l}
J_{1} \ddot{\theta}_{1}+3 K_{c}\left(\theta_{1}-\theta_{2}\right)+k_{e}\left(\theta_{1}-\theta_{3}\right)+c_{s}\left(\dot{\theta}_{1}-\dot{\theta}_{3}\right)=T_{p} \sin \omega t \\
J_{2} \ddot{\theta}_{2}+M_{f} \operatorname{sgn}\left(\dot{\theta}_{2}-\dot{\theta}_{3}\right)=K_{c}\left(\theta_{1}-\theta_{2}\right) \\
J_{3} \ddot{\theta}_{3}+k_{g} \theta_{3}+c_{g} \dot{\theta}_{3}=k_{e}\left(\theta_{1}-\theta_{3}\right)+c_{s}\left(\dot{\theta}_{1}-\dot{\theta}_{3}\right)+3 M_{f} \operatorname{sgn}\left(\dot{\theta}_{2}-\dot{\theta}_{3}\right)
\end{array},\right.
$$

where

The dynamic equations of the 2DOF system are given as

$$
k_{e}= \begin{cases}k_{1}, & \text { if } A<\beta, \\ k_{1}+\frac{1}{\pi}\left(k_{2}-k_{1}\right)\left(2 \Theta_{0}-\sin 2 \Theta_{0}\right), & \text { if } A \geq \beta,\end{cases}
$$

$$
\left\{\begin{array}{l}
J \ddot{\theta}_{1}+k_{e}\left(\theta_{1}-\theta_{3}\right)+c_{s}\left(\dot{\theta}_{1}-\dot{\theta}_{3}\right)=T_{p} \sin \omega t-3 M_{f} \operatorname{sgn}\left(\dot{\theta}_{1}-\dot{\theta}_{3}\right), \\
J_{3} \ddot{\theta}_{3}+k_{g} \theta_{3}+c_{g} \dot{\theta}_{3}=k_{e}\left(\theta_{1}-\theta_{3}\right)+c_{s}\left(\dot{\theta}_{1}-\dot{\theta}_{3}\right)+3 M_{f} \operatorname{sgn}\left(\dot{\theta}_{1}-\dot{\theta}_{3}\right),
\end{array}\right.
$$


where $J=J_{1}+3 J_{2}$.

4.2. Approximate Analytical Solution of the Nonlinear Dynamics Equations. It is known that approximate analytical or semianalytical solutions can be formulated by using the methods of either Krylov-Bogoliubov, Galerkin, Ritz, averaging, harmonic balance, or multiple scales. The method of averaging is valid in the first approximation and can be used to examine the stability behavior. The main idea of the method of averaging is that the derivatives of the amplitude and initial phase of the nonlinear vibration system are regarded as a slowly varying function of time and replaced by the average value of one cycle.

In this work, the method of averaging is used to solve the nonlinear dynamics equations. According to the nonlinear vibration analysis of multiple degrees-of-freedom systems in reference [31], the damping force, axial friction torque, and input excitation in equation (15) are multiplied by a small parameter $\varepsilon$; then, equation (15) is deformed as follows:

$$
\left\{\begin{array}{l}
\ddot{\theta}_{1}=-\frac{1}{J_{1}}\left(3 K_{c}+k_{e}\right) \theta_{1}+3 \frac{1}{J_{1}} K_{c} \theta_{2}+\frac{1}{J_{1}} k_{e} \theta_{3}+\varepsilon \frac{1}{J_{1}}\left(T_{p} \sin \omega t-c_{s}\left(\dot{\theta}_{1}-\dot{\theta}_{3}\right)\right), \\
\ddot{\theta}_{2}=\frac{1}{J_{2}} K_{c} \theta_{1}-\frac{1}{J_{2}} K_{c} \theta_{2}-\varepsilon \frac{1}{J_{2}} M_{f} \operatorname{sgn}\left(\dot{\theta}_{2}-\dot{\theta}_{3}\right), \\
\ddot{\theta}_{3}=\frac{1}{J_{3}} k_{e} \theta_{1}-\frac{1}{J_{3}}\left(k_{e}+k_{g}\right) \theta_{3}+\varepsilon \frac{1}{J_{3}}\left(c_{s}\left(\dot{\theta}_{1}-\dot{\theta}_{3}\right)-c_{g} \dot{\theta}_{3}+3 M_{f} \operatorname{sgn}\left(\dot{\theta}_{2}-\dot{\theta}_{3}\right)\right) .
\end{array}\right.
$$

Let $\theta_{1}=x_{1}, \dot{\theta}_{1}=x_{2}, \theta_{2}=x_{3}, \dot{\theta}_{2}=x_{4}, \theta_{3}=x_{5}, \dot{\theta}_{3}=x_{6}$, $a_{1}=\left(3 K_{c}+k_{e}\right) / J_{1}, \quad a_{2}=3 K_{c} / J_{1}, \quad a_{3}=k_{e} / J_{1}, \quad a_{4}=K_{c} / J_{2}$, $a_{5}=k_{e} / J_{3}, a_{6}=\left(k_{e}+k_{g}\right) / J_{3}$, and when $\varepsilon=0$, equation (18) can be written as

$$
\left\{\begin{array}{l}
\dot{x}_{1}=x_{2} \\
\dot{x}_{2}=-a_{1} x_{1}+a_{2} x_{3}+a_{3} x_{5} \\
\dot{x}_{3}=x_{4} \\
\dot{x}_{4}=a_{4} x_{1}-a_{4} x_{3} \\
\dot{x}_{5}=x_{6} \\
\dot{x}_{6}=a_{5} x_{1}-a_{6} x_{5}
\end{array}\right.
$$

From equation (19), the natural frequency $\omega_{n i}(i=1 \sim 3)$ can be determined by the following formula

$$
\begin{aligned}
& \left(a_{1}-\omega_{n i}{ }^{2}\right)\left(a_{4}-\omega_{n i}{ }^{2}\right)\left(a_{6}-\omega_{n i}{ }^{2}\right) \\
& \quad-a_{2} a_{4}\left(a_{6}-\omega_{n i}{ }^{2}\right)-a_{3} a_{5}\left(a_{4}-\omega_{n i}{ }^{2}\right)=0 .
\end{aligned}
$$

Since the parameters $a_{1}, a_{3}, a_{5}$, and $a_{6}$ contain $k_{\mathrm{e}}$, the natural frequency $\omega_{n i}$ is also a nonlinear function of $A_{i}$. Taking the following transformation,

$$
x_{s}=\sum_{i=1}^{3} A_{i} G_{s i}\left(\varphi_{i}\right), \quad s=1,2,3,4,5,6,
$$

where $A_{i}$ is amplitude and $\varphi_{i}$ is phase, and both are time functions, and $G_{s i}$ is a transformation function.

Inserting equation (21) into equation (18), we get

$$
\sum_{i=1}^{3} \frac{\mathrm{d} A_{i}}{\mathrm{~d} t} G_{s i}\left(\varphi_{i}\right)-\sum_{i=1}^{3} A_{i} G_{s i}^{*}\left(\varphi_{i}\right)\left(\frac{\mathrm{d} \varphi_{i}}{\mathrm{~d} t}-\omega_{n i}\right)=\varepsilon F_{s},
$$

where

$$
\left\{\begin{array}{l}
F_{1}=0, \\
F_{2}=\frac{\left(T_{p} \sin \omega t-c_{s}\left(\dot{\theta}_{1}-\dot{\theta}_{3}\right)\right)}{J_{1}}, \\
F_{3}=0, \\
F_{4}=\frac{-M_{f}}{J_{2} \operatorname{sgn}\left(\dot{\theta}_{2}-\dot{\theta}_{3}\right)}, \\
F_{5}=0, \\
F_{6}=\frac{\left(c_{s}\left(\dot{\theta}_{1}-\dot{\theta}_{3}\right)-c_{g} \dot{\theta}_{3}+3 M_{f} \operatorname{sgn}\left(\dot{\theta}_{2}-\dot{\theta}_{3}\right)\right)}{J_{3}},
\end{array}\right.
$$


A set of fundamental solution of equation (19) is given as

$$
\begin{aligned}
G_{1 i} & =\cos \omega_{n i} t, \\
G_{1 i}^{*} & =\sin \omega_{n i} t \\
G_{2 i} & =-\omega_{n i} \sin \omega_{n i} t, \\
G_{2 i}^{*} & =\omega_{n i} \cos \omega_{n i} t \\
G_{3 i} & =\frac{a_{4}}{a_{4}-\omega_{n i}^{2}} \cos \omega_{n i} t, \\
G_{3 i}^{*} & =\frac{a_{4}}{a_{4}-\omega_{n i}^{2}} \sin \omega_{n i} t \\
G_{4 i} & =-\frac{a_{4} \omega_{n i}}{a_{4}-\omega_{n i}^{2}} \sin \omega_{n i} t, G_{4 i}^{*} \\
& =\frac{a_{4} \omega_{n i}}{a_{4}-\omega_{n i}^{2}} \cos \omega_{n i} t \\
G_{6 i}^{*} & =\frac{a_{5}}{a_{6}-\omega_{n i}^{2}} \cos \omega_{n i} t . \\
G_{5 i} & =-\frac{a_{5} \omega_{n i}}{a_{6}-\omega_{n i}^{2}} \sin \omega_{n i}^{2} t, \\
G_{5 i}^{*} & =\frac{a_{5}}{a_{6}-\omega_{n i}^{2}} \sin \omega_{n i} t, \\
G_{6 i} & =1
\end{aligned}
$$

The adjoint equation of equation (19) is as follows:

$$
\left\{\begin{array}{l}
\dot{X}_{1}=a_{1} X_{2}-a_{4} X_{4}-a_{5} X_{6}, \\
\dot{X}_{2}=-X_{1}, \\
\dot{X}_{3}=-a_{2} X_{2}+a_{4} X_{4}, \\
\dot{X}_{4}=-X_{3} \\
\dot{X}_{5}=-a_{3} X_{2}+a_{6} X_{6}, \\
\dot{X}_{6}=-X_{5}
\end{array}\right.
$$

Also, a set of fundamental solutions of equation (25) can be obtained as follows:

$$
\begin{aligned}
& H_{1 i}=\cos \omega_{n i} t, \\
& H_{1 i}^{*}=\sin \lambda_{i} t \\
& H_{2 i}=-\frac{1}{\omega_{n i}} \sin \omega_{n i} t, \\
& H_{2 i}^{*}=\frac{1}{\omega_{n i}} \cos \omega_{n i} t \\
& H_{3 i}=\frac{a_{2}}{\left(a_{4}-\omega_{n i}^{2}\right)} \cos \omega_{n i} t,
\end{aligned}
$$

$$
\begin{aligned}
& H_{3 i}^{*}=\frac{a_{2}}{\left(a_{4}-\omega_{n i}{ }^{2}\right)} \sin \omega_{n i} t \\
& H_{4 i}=-\frac{a_{2}}{\left(a_{4}-\omega_{n i}^{2}\right)} \frac{1}{\omega_{n i}} \sin \omega_{n i} t \\
& H_{4 i}^{*}=-\frac{a_{2}}{\left(a_{4}-\omega_{n i}{ }^{2}\right)} \frac{1}{\omega_{n i}} \cos \omega_{n i} t \\
& H_{5 i}=\frac{a_{3}}{\left(a_{6}-\omega_{n i}{ }^{2}\right)} \cos \omega_{n i} t, \\
& H_{5 i}^{*}=\frac{a_{3}}{\left(a_{6}-\omega_{n i}^{2}\right)} \sin \omega_{n i} t \\
& H_{6 i}=-\frac{a_{3}}{\left(a_{6}-\omega_{n i}^{2}\right)} \frac{1}{\omega_{n i}} \sin \omega_{n i} t \\
& H_{6 i}^{*}=-\frac{a_{3}}{\left(a_{6}-\omega_{n i}^{2}\right)} \frac{1}{\omega_{n i}} \cos \omega_{n i} t .
\end{aligned}
$$

There is a relationship between formulas (24) and (26):

$$
\begin{aligned}
\sum_{s} G_{s i}^{*}\left(\varphi_{i}\right) H_{s i}^{*}\left(\varphi_{i}\right) & =\sum_{s} G_{s i}\left(\varphi_{i}\right) H_{s i}\left(\varphi_{i}\right) \\
& =1+\frac{a_{2} a_{4}}{\left(a_{4}-\omega_{n i}^{2}\right)^{2}}+\frac{a_{3} a_{5}}{\left(a_{6}-\omega_{n i}^{2}\right)^{2}} \\
& =\Delta_{i} .
\end{aligned}
$$

Multiplying equation (22) by $H_{s i}\left(\varphi_{i}\right)$ and $H_{s i}^{*}\left(\varphi_{i}\right)$, respectively, we obtain

$$
\begin{aligned}
& \frac{d A_{i}}{\mathrm{~d} t}=\frac{\varepsilon}{\Delta_{i}} \sum_{s} F_{s} H_{s i}\left(\varphi_{i}\right)=\varepsilon \phi_{i}\left(A_{i}, \varphi_{i}\right), \\
& \frac{d \varphi_{i}}{\mathrm{~d} t}=\omega_{n i}-\frac{\varepsilon}{\Delta_{i} A_{i}} \sum_{s} F_{s} H_{s i}^{*}\left(\varphi_{i}\right)=\omega_{n i}-\varepsilon \phi_{i}^{*}\left(A_{i}, \varphi_{i}\right) .
\end{aligned}
$$

For $A_{i}$ and $\varphi_{i}$, we take the following transformation:

$$
\begin{aligned}
A_{i} & =y_{i}+\varepsilon U_{i}\left(t, y_{i}, \vartheta_{i}\right), \\
\varphi_{i} & =\omega t+\vartheta_{i}+\varepsilon V_{i}\left(t, y_{i}, \vartheta_{i}\right) .
\end{aligned}
$$

When studying the system main resonance vibration, take $\lambda_{i}-\omega$ as the same order infinitesimal as $\varepsilon$, and require the derivative of new variables $y_{i}, \vartheta_{i}$ as follows:

$$
\begin{aligned}
& \frac{\mathrm{d} y_{i}}{\mathrm{~d} t}=\varepsilon Y_{i}\left(y_{i}, \vartheta_{i}\right)+\varepsilon^{2} Y_{i}^{*}\left(t, y_{i}, \vartheta_{i}, \varepsilon\right), \\
& \frac{\mathrm{d} \vartheta_{i}}{\mathrm{~d} t}=\varepsilon Z_{i}\left(y_{i}, \vartheta_{i}\right)+\varepsilon^{2} Z_{i}^{*}\left(t, y_{i}, \vartheta_{i}, \varepsilon\right) .
\end{aligned}
$$

For equations (29) and (30), $Y_{i}$ and $Z_{i}$ do not contain periodic functions of time $t$, and $U_{i}, V_{i}, Y_{i}^{*}$, and $Z_{i}^{*}$ are the functions of $\vartheta_{i}$ and $t$ with period $2 \pi$. 
Substituting equation (30) into equation (29) and letting the first-order coefficient of $\varepsilon$ be equal, we get

$$
\begin{aligned}
& Y_{i}+\frac{\mathrm{d} U_{i}}{\mathrm{~d} t}=\phi_{i}, \\
& Z_{i}+\frac{\mathrm{d} V_{i}}{\mathrm{~d} t}=-\phi_{i}^{*} .
\end{aligned}
$$
$t$, put

In order to make the functions $Y_{i}$ and $Y_{i}$ not contain time

$$
\begin{aligned}
& Y_{i}=\frac{1}{2 \pi} \int_{0}^{2 \pi} \phi_{i} \mathrm{~d} \psi \\
& Z_{i}=\omega_{n i}-\omega-\frac{1}{2 \pi} \int_{0}^{2 \pi} \phi_{i}^{*} \mathrm{~d} \psi .
\end{aligned}
$$

In equation (30), we take the first-order square coefficient of $\varepsilon$, and let the right end be equal to zero. Because the first-order resonant amplitude is much larger than the second-order and third-order amplitudes, the first-order resonant frequency characteristics are mainly analyzed here. The first-order approximate analytical solution is set as $\theta_{1}=A_{1} \cos \left(\omega t+\varphi_{1}\right), \theta_{2}=a_{4} / a_{4}-\omega_{n 1}^{2} A_{1} \cos \left(\omega t+\varphi_{1}\right), \theta_{3}=$ $a_{5} / a_{6}-\omega_{n 1}^{2} A_{1} \cos \left(\omega t+\varphi_{1}\right)$. After a series of calculation, the following function is obtained:

$$
\left\{\begin{array}{l}
\frac{\mathrm{d} A_{1}}{\mathrm{~d} t}=\varepsilon\left(-\frac{1}{2 J_{1} \omega_{n 1} \Delta_{1}} T_{p} \cos \varphi_{1}-\frac{1}{2 \pi \Delta_{1}}\left(S_{1} A_{1}+S_{2}\right)\right), \\
\frac{\mathrm{d} \varphi_{1}}{\mathrm{~d} t}=\omega_{n 1}-\omega+\varepsilon\left(\frac{1}{2 J_{1} \omega_{n 1} \Delta_{1} A_{1}} T_{p} \sin \varphi_{1}\right),
\end{array}\right.
$$

where

$$
\left\{\begin{array}{l}
S_{1}=\left(\frac{a_{3}}{J_{3}\left(a_{6}-\omega_{n 1}^{2}\right)}-\frac{1}{J_{1}}\right)\left(\frac{a_{5}}{a_{6}-\omega_{n 1}^{2}}-1\right) c_{s} \pi+\frac{a_{3} a_{5}}{J_{3}\left(a_{6}-\omega_{n 1}^{2}\right)^{2}} c_{g} \pi \\
S_{2}=\left(\frac{3 a_{3}}{J_{3}\left(a_{6}-\omega_{n 1}^{2}\right) \omega_{n 1}}-\frac{a_{2}}{J_{2}\left(a_{4}-\omega_{n 1}^{2}\right) \omega_{n 1}}\right) 4 M_{f} \operatorname{sgn}\left(\frac{a_{5}}{a_{6}-\omega_{n 1}^{2}}-\frac{a_{4}}{a_{4}-\omega_{n 1}^{2}}\right) .
\end{array}\right.
$$

The steady-state solution can be found by setting $\mathrm{d} A / \mathrm{d} t=0, \mathrm{~d} \varphi / \mathrm{d} t=0$. The relationship between the system excitation frequency $\omega$ and the amplitude $A_{1}$ and phase $\varphi_{1}$ can be obtained.

$$
\left\{\begin{array}{l}
\omega=\sqrt{\omega_{n 1}^{2}-2\left(\frac{\delta_{e}}{A_{1}}\right)^{2} \pm \sqrt{\left(\frac{T_{p}}{\Delta_{1} J_{1} A_{1}}\right)^{2}+4\left(\frac{\delta_{e}}{A_{1}}\right)^{2}\left(\left(\frac{\delta_{e}}{A_{1}}\right)^{2}-\omega_{n 1}^{2}\right)}} \\
\varphi_{1}=\arctan \frac{\left(\omega^{2}-\omega_{n 1}^{2}\right) A_{1}}{2 \delta_{e} \omega}
\end{array}\right.
$$

where

$$
\delta_{e}=-\frac{1}{2 \pi \Delta_{1}}\left(S_{1} A_{1}+S_{2}\right) .
$$

For the 2DOF model, according to equation (17), the first-order natural frequency of the corresponding linear systems can be given by:

$$
\omega_{n 1}^{\prime}=\sqrt{\frac{1}{2}\left(b_{1}+b_{3}-\sqrt{\left(b_{1}-b_{3}\right)^{2}+4 b_{1} b_{2}}\right)}
$$

where $b_{1}=k_{e} / J, b_{2}=k_{e} / J_{3}, b_{3}=\left(k_{e}+k_{g}\right) / J_{3}$.

Similarly, the first approximate analytical solution of the 2DOF model system can be written as $\theta_{1}=A_{1}^{\prime} \sin \left(\omega t+\varphi_{1}^{\prime}\right)$, $\theta_{3}=\left(b_{1}-\omega_{n 1}^{\prime 2} / b_{1}\right) A_{1}^{\prime} \cos \left(\omega t+\varphi_{1}^{\prime}\right)$, and the relationship between $\omega$ and amplitude $A_{1}^{\prime}$, and phase $\varphi_{1}^{\prime}$ in the first approximate analytical solution are deduced

$$
\left\{\begin{array}{l}
\omega=\sqrt{\omega_{n 1}^{\prime 2}-2\left(\frac{\delta_{e}^{\prime}}{A_{1}^{\prime}}\right)^{2} \pm \sqrt{\left(\frac{T_{p}}{A_{1}^{\prime} J}\right)^{2}+4\left(\frac{\delta_{e}^{\prime}}{A_{1}^{\prime}}\right)^{2}\left(\left(\frac{\delta_{e}^{\prime}}{A_{1}^{\prime}}\right)^{2}-\omega_{n 1}^{\prime 2}\right)}} \\
\varphi_{1}^{\prime}=\arctan \frac{\left(\omega^{2}-\omega_{n 1}^{\prime 2}\right) A_{1}^{\prime}}{2 \delta_{e}^{\prime} \omega}
\end{array}\right.
$$


where

$$
\begin{aligned}
\delta_{e}^{\prime}= & -\frac{1}{2 \pi \Delta_{1}^{\prime}}\left(Q_{1} A_{1}^{\prime}+Q_{2}\right) \\
& \cdot\left\{\begin{array}{l}
Q_{1}=\left(\frac{\left(b_{1}-\omega_{n 1}^{2}\right)^{2}}{b_{1} b_{2} J_{3}} c_{g}-\left(\frac{b_{1}-\omega_{n 1}^{\prime 2}}{b_{2} J_{3}}-\frac{1}{J}\right) \frac{\omega_{n 1}^{\prime 2}}{b_{1}} c_{s}\right) \pi, \\
Q_{2}=-\frac{12}{\omega_{n 1}^{\prime}}\left(\frac{b_{1}-\omega_{n 1}^{\prime 2}}{b_{2} J_{3}}-\frac{1}{J}\right) M_{f} .
\end{array}\right.
\end{aligned}
$$

Equations (35) and (38) are the nonlinear relationship between the excitation frequency and amplitude and initial phase, which can be solved by numerical method to obtain the corresponding amplitude-frequency characteristics and phase-frequency characteristics.

For rotor systems, angular displacement transmissibility is one of the important indexes of vibration reduction performance. The torsional angle amplitude ratio of the secondary flywheel and the primary flywheel $T_{r}$ and $T_{r}^{\prime}$ is the angular displacement transmissibility of the $3 \mathrm{DOF}$ model and the 2DOF model, respectively, which can be expressed as

$$
\left\{\begin{array}{l}
T_{r}=\frac{a_{5}}{a_{6}-\omega_{n 1}^{2}}, \\
T_{r}^{\prime}=\frac{b_{1}-\omega_{n 1}^{\prime 2}}{b_{1}} .
\end{array}\right.
$$

We define the moment inertia ratio $\lambda=J_{2} / J_{1}$, and the main parameters of the DMF are as follows: $r=60 \mathrm{~mm}$, $R=92.5 \mathrm{~mm}, \quad J_{1}=0.15 \mathrm{~kg} \cdot \mathrm{m}^{2}, \quad \lambda=0.02, \quad J_{3}=0.055 \mathrm{~kg} \cdot \mathrm{m}^{2}$, $l=70.9 \mathrm{~mm}, \quad e=16 \mathrm{~mm}, \quad K_{c}=20000 \mathrm{~N} \cdot \mathrm{m} / \mathrm{rad}, h=10 \mathrm{~mm}$, $k_{\mathrm{g}}=501 \mathrm{~N} \cdot \mathrm{m} /{ }^{\circ}, \beta=16^{\circ}, k_{1}=9.22 \mathrm{~N} \cdot \mathrm{m} /{ }^{\circ}, k_{2}=23.67 \mathrm{~N} \cdot \mathrm{m} /{ }^{\circ}$, and $M_{f}=2 \mathrm{~N} \cdot \mathrm{m}$. The synthesis elastic modulus $E^{*}$ can be calculated with the material properties of the primary flywheel pressure plate and friction damping ring shown in Table 1.

To verify the correctness of the solution method in Section 3.2, the Runge-Kutta numerical method is applied to obtain the amplitude-frequency characteristics of the primary flywheel angular displacement of the 3DOF model and $2 \mathrm{DOF}$ when $T_{p}=100 \mathrm{~N} \cdot \mathrm{m}$. As shown in Figure $7(\mathrm{a})$, the numerical results agree with the current analytical results well at different frequencies, which indicates that the calculation and analysis of the averaging method are accurate and valid. The commonly used speed of the vehicle engine is 800-4000 rpm, corresponding to the angular frequency range of $83.8-418.9 \mathrm{rad} / \mathrm{s}$. From equation (20), the firstorder and second-order resonant frequencies of the system are about $57 \mathrm{rad} / \mathrm{s}$ and $728 \mathrm{rad} / \mathrm{s}$, respectively, while the third-order resonant frequency is higher, so the resonant frequency range of the system can avoid in the frequency range of the engine torque variation. In addition, through numerical analysis, it is found that the response amplitude of the second-order and third-order resonant frequencies is also much smaller than that of the first-order resonant frequency. Therefore, we mainly analyze the first-order resonant frequency characteristics without considering the second-order and third-order resonant frequency characteristics in Section 3.2.

The first-order resonance amplitude-frequency characteristics of the 2DOF model and 3DOF model under different excitation torque amplitudes $T_{p}$ are shown in Figure 7(b). It can be seen that the larger the excitation torque, the larger the overall response amplitude and the wider the resonance frequency band. Under the same excitation frequency, the amplitude of the 3DOF model is smaller than that of the $2 \mathrm{DOF}$ model, especially nearby the resonant frequency. The maximum value of the $3 \mathrm{DOF}$ model is $10.2^{\circ}, 20.7^{\circ}$, and $28.7^{\circ}$ when $T_{\mathrm{p}}=40 \mathrm{~N} \cdot \mathrm{m}, 80 \mathrm{~N} \cdot \mathrm{m}$, and $120 \mathrm{~N} \cdot \mathrm{m}$, respectively, while the maximum value of the 2DOF model is $10.9^{\circ}, 21.6^{\circ}$, and $30.2^{\circ}$. Since the 3DOF model takes into account the elastic deformation under the contact action of the structure, it is more closer to the actual situation. Next, the frequency characteristics, angular displacement transmissibility, and forced vibration of the 3DOF model are mainly analyzed.

The effects of the moment inertia ratio $\lambda$, DMF stiffness $k_{e}$, and contact stiffness $K_{c}$ on the natural frequency of the $3 \mathrm{DOF}$ model can be analyzed, respectively from equation (20), as shown in Figure 8. When $\lambda$ changes from 0 to 0.1 , as shown in Figure $8(\mathrm{a})$, the first-order natural frequency changes from $58.8 \mathrm{rad} / \mathrm{s}$ to $51.6 \mathrm{rad} / \mathrm{s}$, the third-order natural frequency changes from $36520.3 \mathrm{rad} / \mathrm{s}$ to $1316.8 \mathrm{rad} / \mathrm{s}$, while the second-order natural frequency basically maintains at $729.1 \mathrm{rad} / \mathrm{s}$. Therefore, $J_{2}$ has a great influence on the firstorder and third-order natural frequencies but little influence on the second-order natural frequencies. Figure 8(b) demonstrates that when the torsional stiffness $k_{e}$ changes from $0 \mathrm{~N} \cdot \mathrm{m} /{ }^{\circ}$ to $30 \mathrm{~N} \cdot \mathrm{m} /{ }^{\circ}$, the first-order natural frequency $\omega_{\mathrm{n} 1}$ changes from 0 to $100.9 \mathrm{rad} / \mathrm{s}$, and the second-order and third-order natural frequencies are about $729.1 \mathrm{rad} / \mathrm{s}$ and $2658.3 \mathrm{rad} / \mathrm{s}$, respectively. Therefore, $k_{e}$ mainly affects the first-order natural frequency and has little influence on the second- and third-order natural frequencies. Besides, from Figure 8(c), it can be concluded that the contact stiffness $K_{c}$ mainly affects the third-order natural frequency and has little effect on the first-order and second-order natural frequency.

\section{Steady-State Response Frequency Characteristics}

Based on the above analysis and considering that the axial friction torque has the damping equivalent effect to decrease the vibration, the influence of the moment inertia of the friction damping ring $J_{2}$, the DMF stiffness $\left(k_{1}\right.$ and $\left.k_{2}\right)$, and the axial friction torque $M_{f}$ on the nonlinear amplitudefrequency characteristics of the 3DOF model is to study below.

When the other parameters remain unchanged and the moment inertia ratio $\lambda$ is given as $0.01,0.02,0.1$, and 0.5 , the first-order amplitude-frequency characteristic curves are shown in Figure 9(a). With the increase of $\lambda$, the first-order resonant frequency becomes small, and the overall 
TABle 1: Material properties.

\begin{tabular}{lcc}
\hline Properties/bodies & Primary flywheel pressure plate & Friction damping ring \\
\hline Material & Steel & Pa66 \\
Elastic modulus $(\mathrm{GPa})$ & 206 & 8.3 \\
Poisson ratio & 0.3 & 0.28 \\
\hline
\end{tabular}
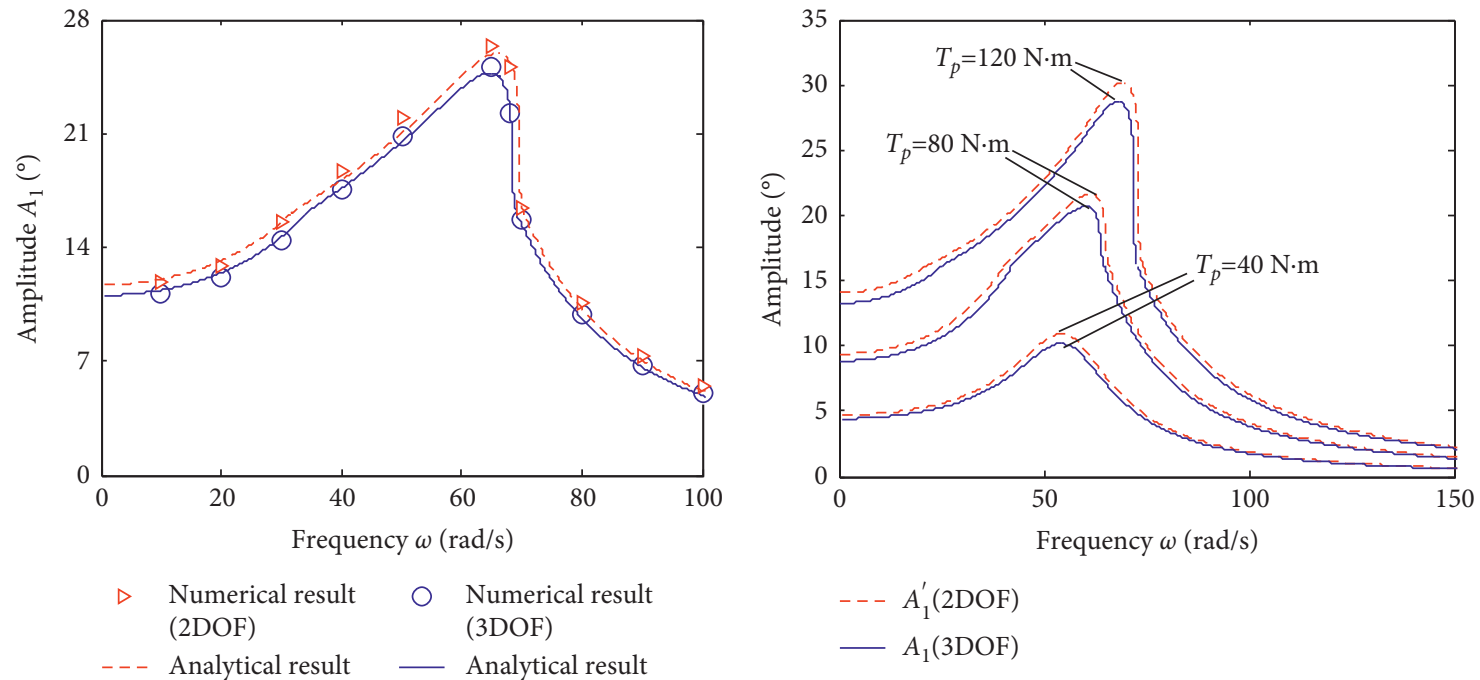 (2DOF) (3DOF)
- - - Analytical result _ Analytical result (2DOF) (3DOF)

$\triangleright \quad$ Numerical result

$\bigcirc$ Numerical result$$
-A_{1}(3 \mathrm{DOF})
$$

(b)

FIGURE 7: Amplitude-frequency characteristics of the primary flywheel angular displacement. (a) Comparison of the numerical method result and the analytical result of the $3 \mathrm{DOF}$ model and $2 \mathrm{DOF}$ model when $T_{p}=100 \mathrm{~N} \cdot \mathrm{m}$. (b) Comparison of the 3DOF model and $2 \mathrm{DOF}$ model with different $T_{p}$.

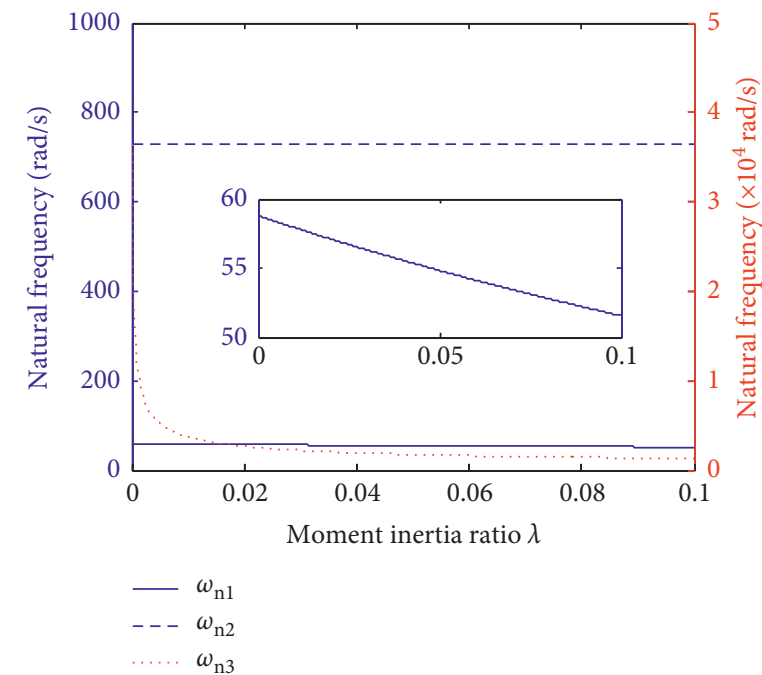

(a)

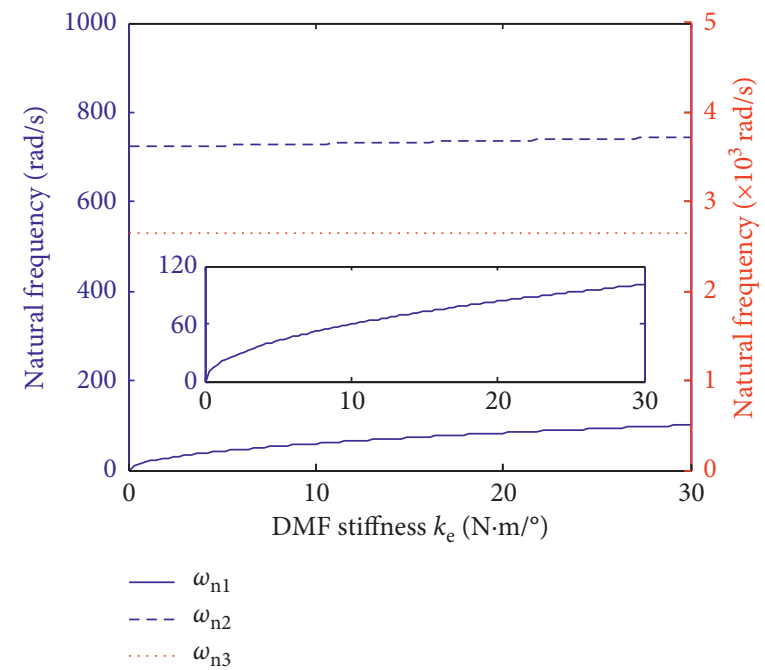

(b)

FIGURE 8: Continued. 


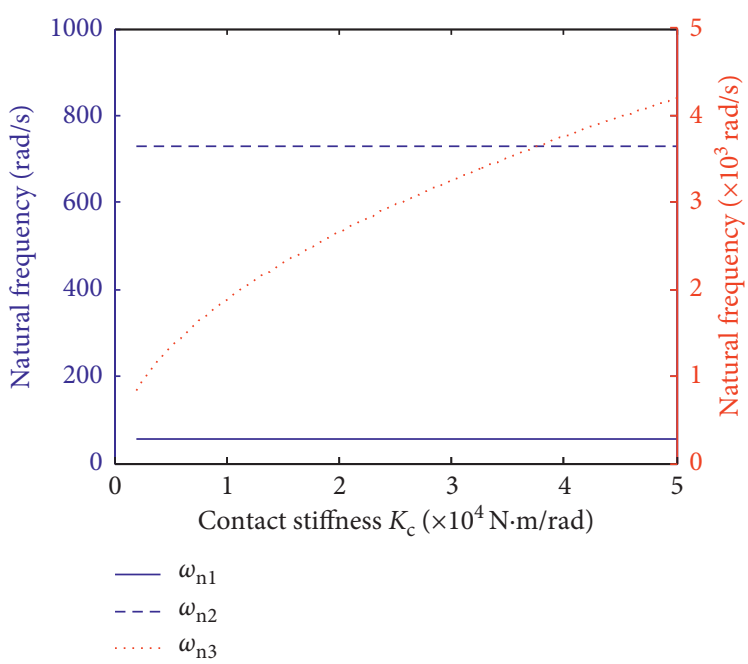

(c)

Figure 8: Influence of $\lambda, k_{e}$ and $K_{c}$ on the natural frequency of the 3DOF model. (a) Influence of $\lambda$. (b) Influence of $k_{e}$. (c) Influence of $K_{\mathrm{c}}$.
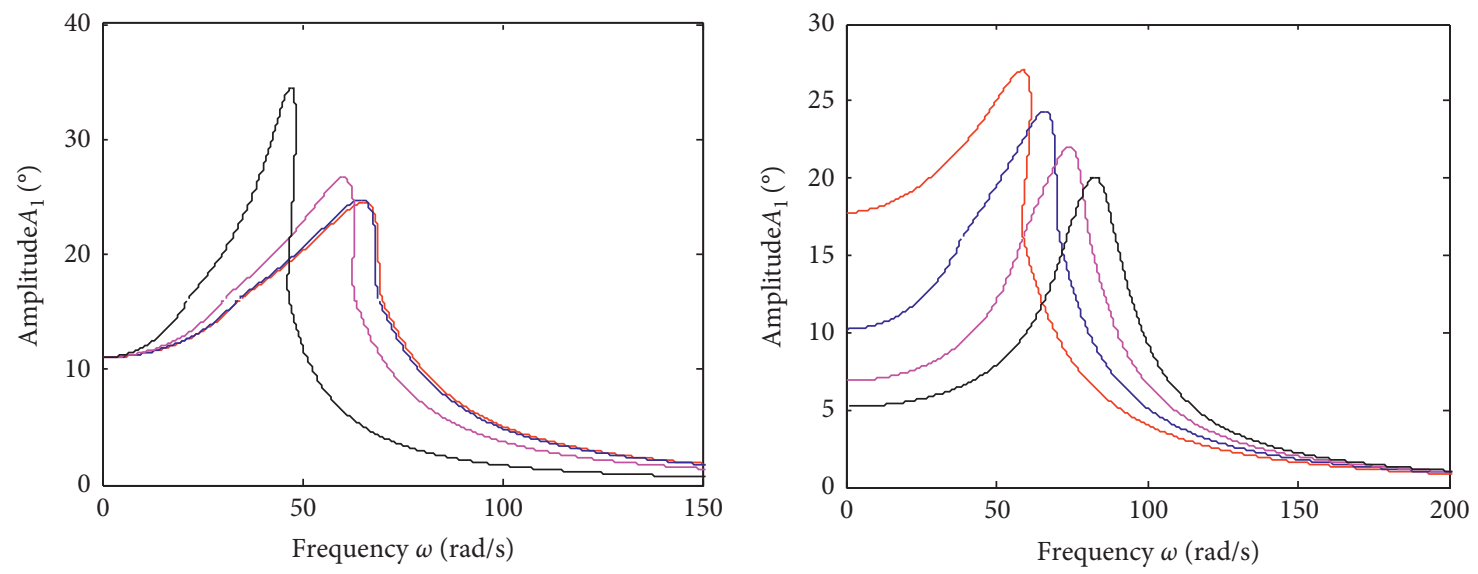

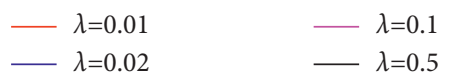

(a)

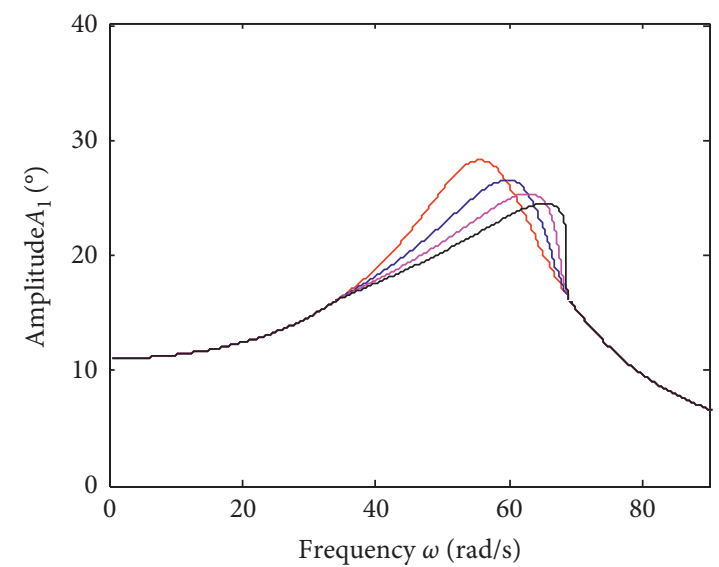

$k_{1}=5 \mathrm{~N} \cdot \mathrm{m} /{ }^{\circ} \quad k_{1}=15 \mathrm{~N} \cdot \mathrm{m} /{ }^{\circ}$

$-k_{1}=10 \mathrm{~N} \cdot \mathrm{m} /{ }^{\circ} \quad-k_{1}=20 \mathrm{~N} \cdot \mathrm{m} /{ }^{\circ}$

(b)

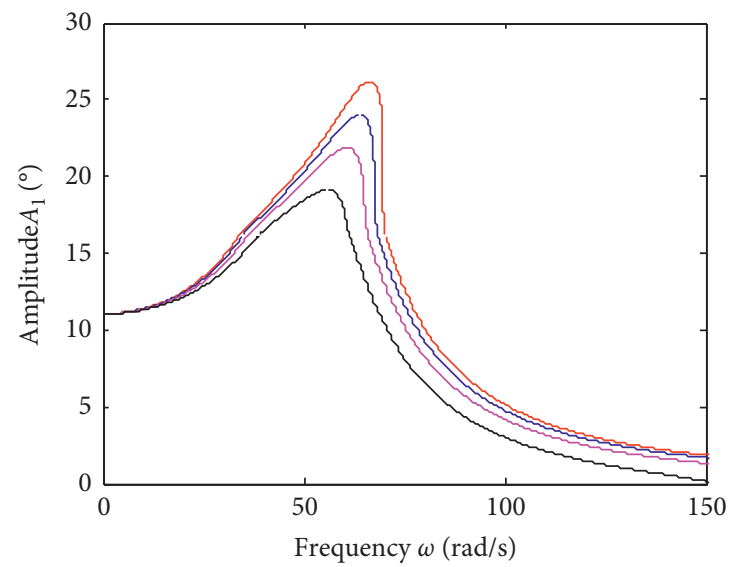

$\begin{array}{ll}M_{f}=0 \mathrm{~N} \cdot \mathrm{m} & -M_{f}=6 \mathrm{~N} \cdot \mathrm{m} \\ M_{f}=3 \mathrm{~N} \cdot \mathrm{m} & -M_{f}=10 \mathrm{~N} \cdot \mathrm{m}\end{array}$

(d)

(c)

FIGURE 9: Amplitude-frequency characteristics of the primary flywheel angular displacement. (a) Influence of $\lambda$. (b) Influence of $k_{1}$. (c) Influence of $k_{2}$. (d) Influence of $M_{f}$. 
amplitude nearby resonant frequency will increase. Therefore, the moment inertia of the friction damping ring $J_{2}$ increases, the frequency of the resonance region will be significantly decreased, but the amplitude will also be significantly increased.

When $k_{1}$ is taken as $5 \mathrm{~N} \cdot \mathrm{m} /{ }^{\circ}, 10 \mathrm{~N} \cdot \mathrm{m} /{ }^{\circ}, 15 \mathrm{~N} \cdot \mathrm{m} /{ }^{\circ}$, and $20 \mathrm{~N} \cdot \mathrm{m} /{ }^{\circ}$, respectively, the amplitude-frequency characteristic curves are shown in Figure 9(b). It can be found that with the increase of $k_{1}$, the corresponding amplitude-frequency characteristic curve moves to the right, namely the resonance frequency increases, but the response amplitude at the resonance frequency will decrease.

In Figure 9(c), the amplitude-frequency characteristic curve is given when $k_{2}$ is $10 \mathrm{~N} \cdot \mathrm{m} /{ }^{\circ}, 15 \mathrm{~N} \cdot \mathrm{m} / /^{\circ}, 20 \mathrm{~N} \cdot \mathrm{m} /{ }^{\circ}$, and $25 \mathrm{~N} \cdot \mathrm{m} /{ }^{\circ}$, respectively. It can be concluded that the secondstage stiffness $k_{2}$ of the DMF has a great influence on the amplitude-frequency characteristics of the resonance region. With the increase of $k_{2}$, the overall amplitude decreases, and the amplitude-frequency characteristic curve moves to the right, namely the resonant frequency increases. The main reason is that when $A \geq \beta$, with the increase of $k_{2}$, the equivalent stiffness $k_{e}$ of the system increases, and the firstorder natural frequency increases simultaneously, as shown in Figure 8(a).

Figure 9(d) shows the amplitude-frequency characteristics when the axial friction torque $M_{f}$ equals $0 \mathrm{~N} \cdot \mathrm{m}, 3 \mathrm{~N} \cdot \mathrm{m}$, $6 \mathrm{~N} \cdot \mathrm{m}$, and $10 \mathrm{~N} \cdot \mathrm{m}$, respectively. The resonance regions corresponding to different axial friction torque $M_{f}$ are basically the same, but the amplitudes at the same frequency are different. With the increase of $M_{f}$, the overall amplitude decreases, especially the peak value at the resonance frequency decreases significantly, and the resonance frequency band becomes narrow. Therefore, increasing the axial friction torque is beneficial to reduce the vibration of the system near the resonant frequency. But, because the friction between the parts will cause energy dissipation, excessive axial friction torque will increase fuel consumption and aggravate the wear and service life of the parts in the normal driving process of the vehicle.

\section{Angular Displacement Transfer Characteristics}

Figure 10 shows the angular displacement transmissibility near the first-order resonance frequency region when $T_{p}=100 \mathrm{~N} \cdot \mathrm{m}$. The comparison of the angular displacement transmissibility of the 3DOF model and the 2DOF model is depicted in Figure 10(a). It can be seen that with the increase of frequency, the transmissibility first keeps about 0.018 . When the frequency gradually approaches the resonance frequency, it increases to the maximum value and finally decreases to a stable value of about 0.018 with the continuous increase of frequency. Compared to the $2 \mathrm{DOF}$ model, the angular displacement transmissibility of the $3 \mathrm{DOF}$ model is less in the frequency region of 30-70 rad/s. The maximum transmissibility is about 0.026 and 0.025 for $2 \mathrm{DOF}$ model and 3DOF model, respectively.

Figure 10(b) shows the angular displacement transmissibility under different moment inertia ratios $\lambda$. With the increase of $\lambda$, the angular displacement transmissibility curve moves to the left, and the peak value of the transmissibility becomes higher. But the angular displacement transmissibility far from the resonance frequency region is similar.

Angular displacement transmissibility with different first-stage stiffness $k_{1}$ of the DMF is shown in Figure 10(c). The maximum angular displacement transmissibility is at the resonant frequency. The parameter of $k_{1}$ has a great influence on transmissibility. The larger $k_{1}$ is, the higher the transmissibility is, but the smoother the change process of the transmissibility is.

Figure 10(d) shows the angular displacement transmissibility when the second-stage stiffness $k_{2}$ of the DMF is given different value. In the frequency region $30-70 \mathrm{rad} / \mathrm{s}$, the angular displacement transmissibility corresponding for different $k_{2}$ varies greatly. With the increase of $k_{2}$, the angular displacement transmissibility and the frequency corresponding to the maximum transmissibility become larger. When the frequency is far away from the resonance frequency region, the angular displacement transmissibility with different $k_{2}$ is basically the same, which is about 0.018 , and the larger the $k_{2}$ is, the faster the transmissibility changes with frequency.

Figure 10(e) shows the angular displacement transmissibility with different axial friction torques $M_{f}$. In the resonance frequency range, the larger the $M_{f}$ is, the smaller the angular displacement transmissibility is. And the angular displacement transmissibility is almost the same at far away from resonance frequency, which is about 0.018 .

\section{Forced Vibration Response}

According to the torsional vibration differential equation (15), the forced vibration response of the system of the 3DOF model is analyzed by using the fourth-order Runge-Kutta numerical method. The first-order nonlinear resonance frequency of the system is about $64.5 \mathrm{rad} / \mathrm{s}$. Let the amplitude of the input excitation torque be $100 \mathrm{~N} \cdot \mathrm{m}$, the excitation frequency be $100 \mathrm{rad} / \mathrm{s}$, and all of the initial angular displacements and angular velocities be zeros. The dynamic response of the primary flywheel, friction damping ring, and the second flywheel are shown in Figure 11(a). The amplitude of the angular displacement of the primary flywheel is close to the angular displacement of the friction damping ring, which is about $5^{\circ}$ and basically the same as the approximate solution result. Figure 11(b) shows the variation of the relative angular displacement between the friction damping ring and the primary flywheel, which presents a complex variation. The maximum relative angular displacement is about $0.02^{\circ}$, and the corresponding maximum torque caused by conformal contact is $6.98 \mathrm{~N} \cdot \mathrm{m}$. Therefore, the contact elastic deformation and stress on the contact region of the friction damping ring and the primary flywheel pressure plate are also changed with time under the variable torque excitation during the working process.

When the excitation frequency equals to the first-order nonlinear resonance frequency $64.5 \mathrm{rad} / \mathrm{s}$, and the initial angular displacement and angular velocity are all zeros, the dynamic responses of the 3DOF are shown in Figure 12(a). It 


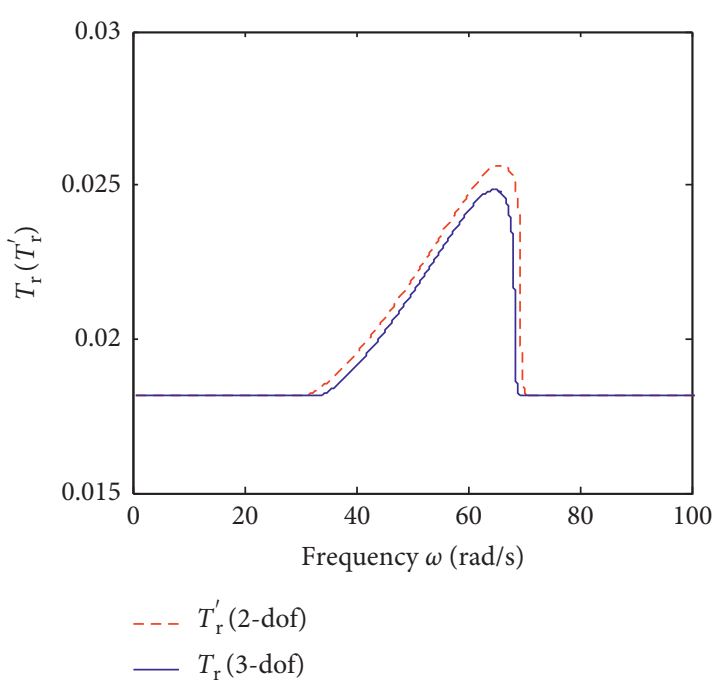

(a)

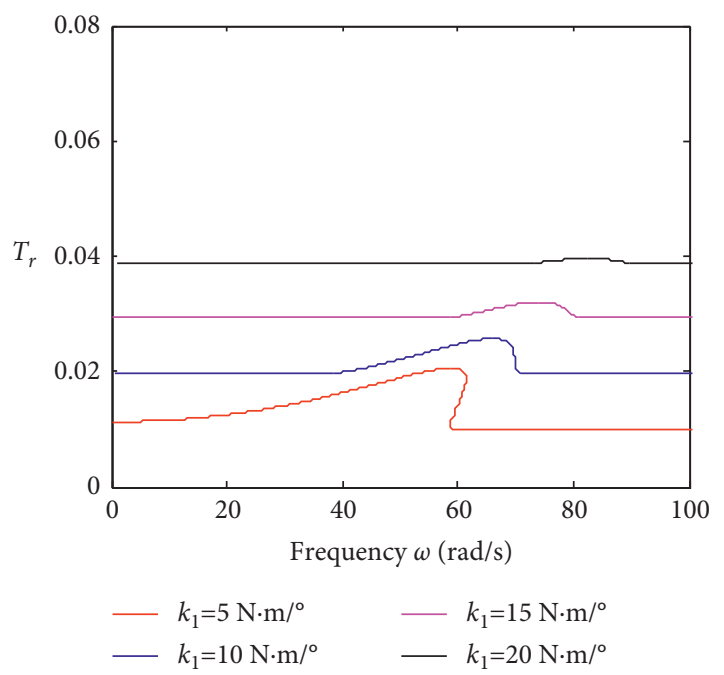

(c)

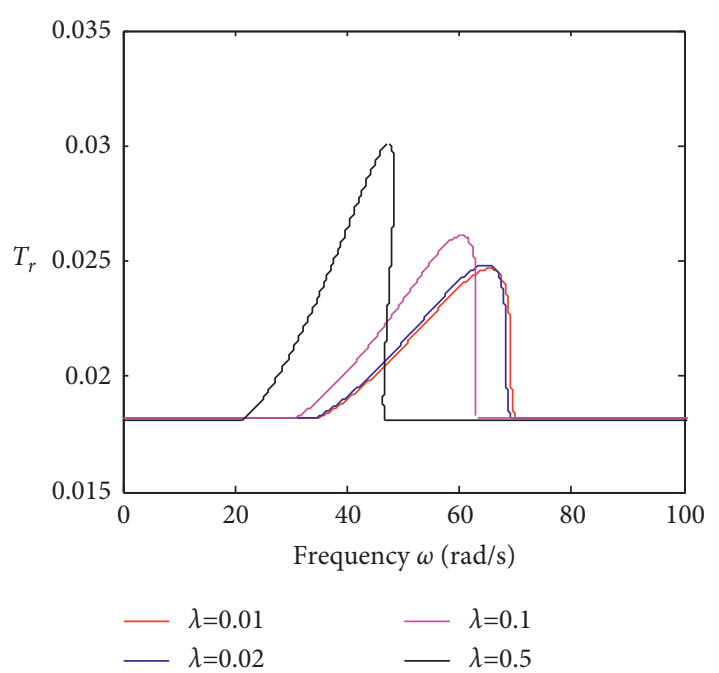

(b)

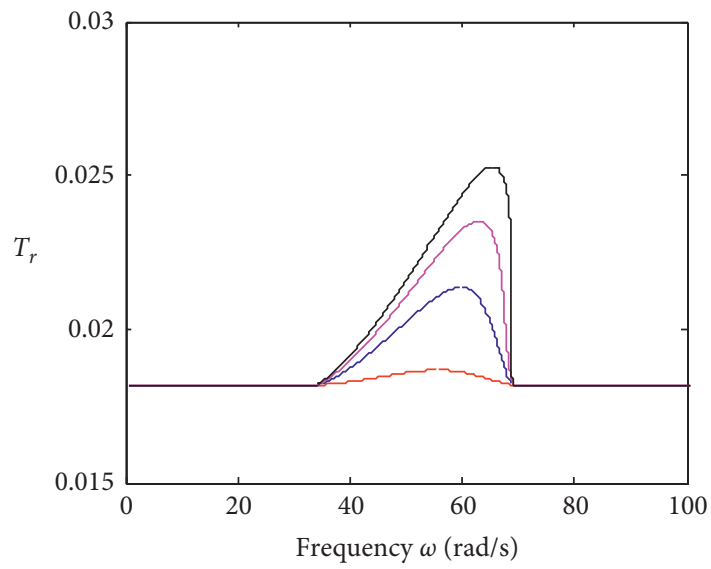

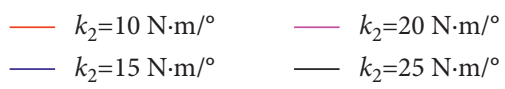

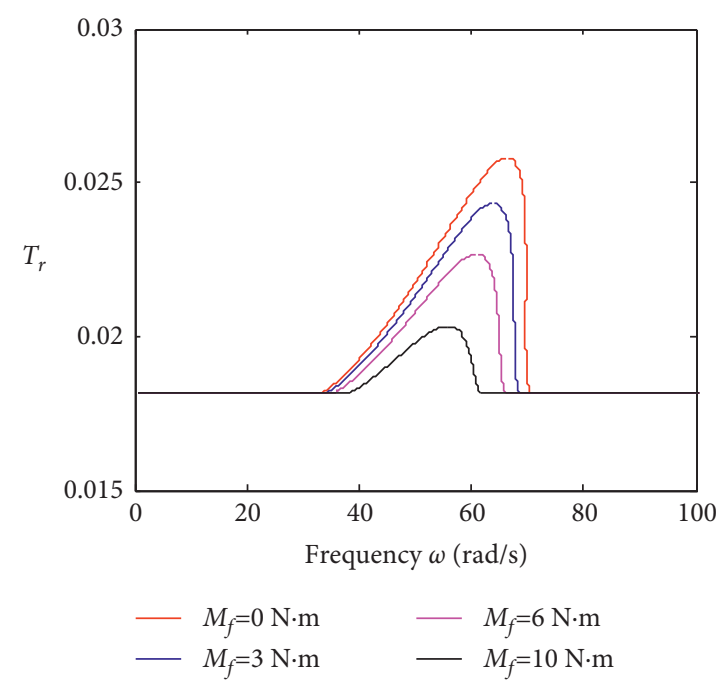

(d)

(e)

Figure 10: Variation of angular displacement transmissibility $T_{r}$ with frequency. (a) Comparison of 3DOF model and 2DOF model. (b) Influence of $\lambda$. (c) Influence of $k_{1}$. (d) Influence of $(k)_{2}$. (e) Influence of $M_{f}$. 


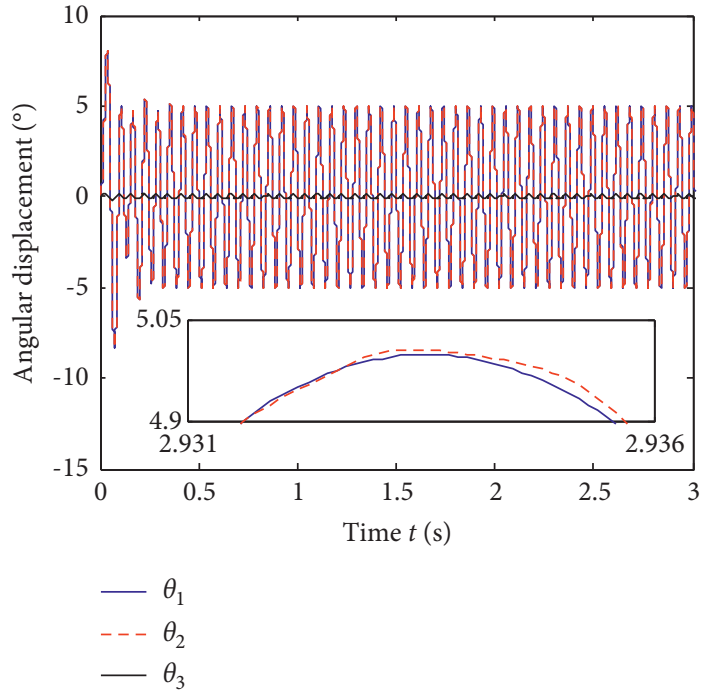

(a)

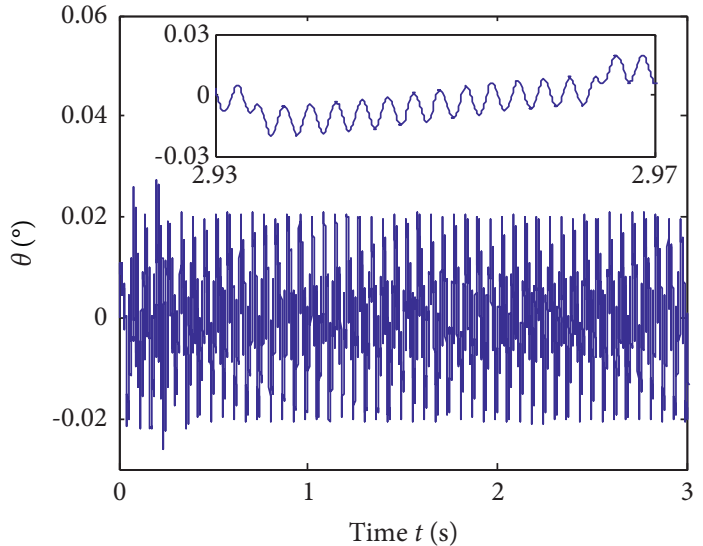

(b)

FIgURe 11: Angular displacement time history with $T_{p}=100 \mathrm{~N} \cdot \mathrm{m}$ and $\omega=100 \mathrm{rad} / \mathrm{s}$. (a) Time history of $\theta_{1}, \theta_{2}$, and $\theta_{3}$. (b) Time history of $\theta$.

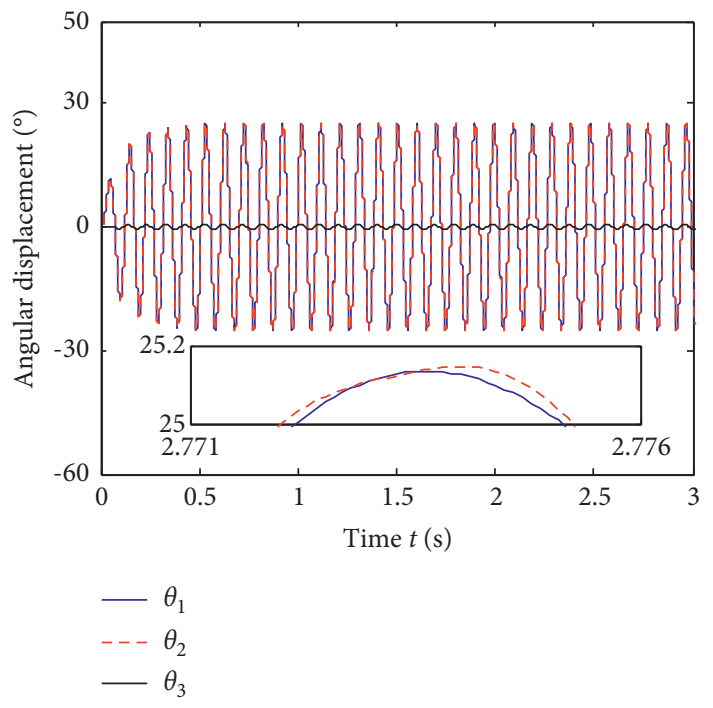

(a)

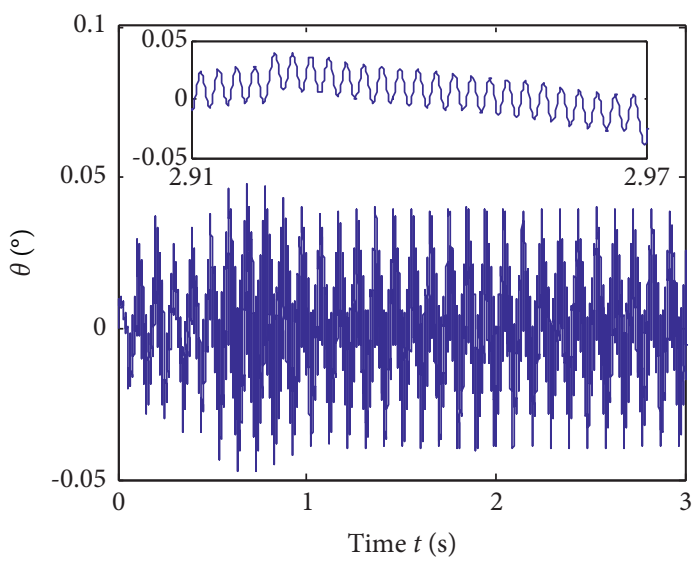

(b)

Figure 12: Angular displacement time history with $T_{p}=100 \mathrm{~N} \cdot \mathrm{m}$ and $\omega=64.5 \mathrm{rad} / \mathrm{s}$. (a) Time history of $\theta_{1}, \theta_{2}$, and $\theta_{3}$. (b) Time history of $\theta$.

can be seen that the primary flywheel, the friction damping ring, and the secondary flywheel have large amplitudes for the system resonates. The change of the angular displacement of the friction damping ring and the primary flywheel is still relatively close, and the amplitudes of both are about $25.2^{\circ}$. The maximum relative angular displacement shown in Figure $12(\mathrm{~b})$ is about $0.04^{\circ}$, and the corresponding maximum torque caused by conformal contact is $13.96 \mathrm{~N} \cdot \mathrm{m}$. Compared with the primary flywheel, the amplitude of the secondary flywheel is also smaller, which is basically the same as the results of the averaging method. Figures 11 and 12 show that the angular displacement amplitude of the secondary flywheel is obviously smaller than that of the primary flywheel after the damping effect of the DMF, indicating that the DMF has very excellent damping performance.

\section{Conclusions}

In order to study the nonlinear dynamic characteristics of the DMF under the conformal contact action between the friction damping ring and the primary flywheel pressure plate, a conformal contact analysis model based on the Winkler model is established. The contact deformation, contact pressure at different contact positions, and equivalent torsional contact stiffness are analyzed. Then, two nonlinear dynamic analysis models of the DMF are established, and the averaging method is used to derive the approximate analytical solution of the nonlinear frequency characteristics of the system at steady state. The theoretical analysis process is proved to be valid by comparing with the response amplitude of the system at steady state analyzed by applying Runge-Kutta numerical method. It 
is found that the structural conformal contact has a certain influence on the nonlinear dynamic characteristics of the system. The overall amplitude and angular displacement transmissibility of the 3DOF model considering the conformal contact effect are smaller than the 2DOF model, especially at resonance frequency. Besides, the $3 \mathrm{DOF}$ which considering the conformal contact of the friction ring is more in line with the actual situation. When $J_{2}$ is small, the result of $2 \mathrm{DOF}$ model is close to 3DOF model. And with the increase of $J_{2}$, the difference between the 2DOF model and 3DOF model results will become larger.

The influences of the moment inertia ratio $\lambda$, DMF stiffness, and axial friction torque $M_{f}$ on the dynamic response frequency characteristics and angular displacement transmissibility of the 3DOF model are analyzed. The results indicate that the first-order natural frequency concerned in this study is mainly affected by the friction damping ring moment inertia $J_{2}$ and DMF stiffness $k_{e}$. The frequency of the resonance region will be significantly decreased with the increase of the friction damping ring moment inertia $J_{2}$, but the amplitude of the system vibration will also turn larger. When the first-stage stiffness of the DMF $k_{1}$ increases, the resonance frequency will increase, but the response amplitude at the resonance frequency decreases. The overall amplitude decreases significantly, but the resonant frequency increases with the increase of the second-stage stiffness of the DMF $k_{2}$. The increase of the axial friction torque $M_{f}$ will make the overall amplitude decrease.

The angular displacement transmissibility reaches the maximum at the resonance frequency. In the resonance frequency region, the increase of $\lambda$ or $k_{2}$ and the decrease of $M_{f}$ make the angular displacement transmissibility become larger. At the frequency away from resonance frequency region, the effect of each one of $\lambda, k_{2}$, and $M_{f}$ parameters on transmissibility is small. The parameter of $k_{1}$ has a great influence on the transmissibility: the larger $k_{1}$ is, the higher the transmissibility is.

For the variation of the relative angular displacement between the friction damping ring and the primary flywheel pressure plate, the contact elastic deformation and stress on the contact region of the friction damping ring and the primary flywheel pressure plate are changing with time under the variable torque excitation during the working process. The angular displacement amplitude of the secondary flywheel is obviously smaller than that of the primary flywheel after the damping effect of the DMF, indicating that the DMF has very excellent damping performance.

\section{Data Availability}

The data used to support the findings of this study are included within the article.

\section{Conflicts of Interest}

The authors declare no conflicts of interest.

\section{Acknowledgments}

This work was supported by the National Natural Science Foundation of China (Grant no. 51805167), Natural Science
Foundation of Jiangxi Province (Grant no. 20171BAB216029), and the Foundation of Educational Department of Jiangxi Province (Grant no. GJJ170403).

\section{References}

[1] H. Y. Isaac, C. Jia-Shiun, D. M. Keith, and Z. Joe, "NVH analysis of balancer chain drives with the compliant sprocket of the crankshaft with a dual-mass-flywheel for an inline-4 engine," in Proceedings of the SAE 2007 Noise and Vibration conference, Grand Rapids, MI, USA, 2007.

[2] T. S. Kang, S. K. Kauh, and K. P. Ha, "Development of the displacement measuring system for a dual mass flywheel in a vehicle," Proceedings of the Institution of Mechanical Engineers - Part D: Journal of Automobile Engineering, vol. 223, no. 10, pp. 1273-1281, 2009.

[3] A. Balluchi, L. Benvenuti, C. Lemma, P. Murrieri, and A. Sangiovanni, "Hybrid models of an automotive driveline," Technical report, PARADES, Rome, 2004.

[4] S. Theodossiades, M. Gnanakumarr, H. Rahnejat, and P. Kelly, "Effect of a dual-mass flywheel on the impact-induced noise in vehicular powertrain systems," Proceedings of the Institution of Mechanical Engineers-Part D: Journal of Automobile Engineering, vol. 220, no. 6, pp. 747-761, 2006.

[5] E. Güllü, A. Ylmaz, and H. Gkda, "Influence of single and dual mass flywheel usage in IC engines on the resonance behavior of the power transmission system," International Journal of Automotive Science And Technology, vol. 3, no. 4, pp. 102-108, 2019.

[6] L. Chen, X. Zhang, Z. F. Yan, and R. Zeng, "Matching model of dual mass flywheel and power transmission based on the structural sensitivity analysis method," Symmetry, vol. 11, 2019.

[7] D. Maffiodo, R. Sesana, D. Paolucci, and S. Bertaggia, "Finite life fatigue design of spiral springs of dual-mass flywheels: analytical estimation and experimental results," Advances in Mechanical Engineering, vol. 10, no. 6, pp. 1-13, 2018.

[8] V. Berbyuk, "Design optimization of torsional vibration absorbers for heavy-duty truck drivetrain systems," Vibrations, vol. 2, no. 3, pp. 240-264, 2019.

[9] L. Q. Song, L. P. Zeng, S. P. Zhang, J. D. Zhou, and H. E. Niu, "Design and analysis of a dual mass flywheel with continuously variable stiffness based on compensation principle," Mechanism and Machine Theory, vol. 79, pp. 124-140, 2014.

[10] S. Sangue, G. Lepoint, and T. L. Bournault, "New approach to measure instantaneous angular behaviour of a dual mass flywheel," in Proceedings of the FISITA World Automotive Congress, pp. 12-15, Seoul, Republic of Korea, May 2000.

[11] X. Tang, X. Hu, W. Yang, and H. Yu, "Novel torsional vibration modeling and assessment of a power-split hybrid electric vehicle equipped with a dual-mass flywheel," IEEE Transactions on Vehicular Technology, vol. 67, no. 3, pp. 1990-2000, 2018.

[12] L. Chen, W. K. Shi, and Z. Y. Chen, "Modeling and experimental study on dynamic characteristics of dual-mass flywheel torsional damper," Shock And Vibration, vol. 2019, Article ID 5808279, 13 pages, 2019.

[13] E. Güllü and A. Ylmaz, "Influence of single and dual mass flywheel usage in IC engines on clutch dynamics," International Journal of Automotive Science And Technology, vol. 4, no. 2, pp. 40-48, 2020.

[14] G. H. Li, J. J. Hu, and D. T. Qin, "Study on natural torsional vibration characteristics of dual mass flywheel-radial spring type torsional vibration damper," China Mechanical Engineering, vol. 19, no. 15, pp. 1800-1805, 2008. 
[15] Y. Mao, Z. Y. Chen, W. K. Shi, and G. Wu, "Torsional vibration damping characteristics of magneto-rheological fluid dual mass flywheel," Journal of Xi'an Jiaotong University, vol. 48, no. 6, pp. 127-133, 2014.

[16] Q. H. Zu, Z. Y. Chen, W. K. Shi, Y. Mao, and Z. Y. Chen, "Torsional Vibration Semiactive Control of Drivetrain Based on Magnetorheological Fluid Dual Mass Flywheel," Mathematical Problems in Engineering, vol. 2015, Article ID 608737, 17 pages, 2015.

[17] Z. Y. Chen, Y. Mao, W. K. Shi, and G. H. Zhang, Control Research of Power Train Torsional Vibration Based on Magneto-Rheological Fluid Dual Mass Flywheel, SAE, Warrendale, PA, USA, Technical Paper, 2014-01-2867, 2014.

[18] L. Song, J. D. Zhou, and R. H. Wu, "Research and application on design theory of friction dual mass flywheel with doublestage piecewise variable stiffness," Journal of Mechanical Engineering, vol. 48, no. 15, pp. 150-157, 2012.

[19] Y. Wang, X. Qin, S. Huang, and S. Deng, "Design and analysis of a multi-stage torsional stiffness dual mass flywheel based on vibration control," Applied Acoustics, vol. 104, pp. 172-181, 2016.

[20] W. K. Shi, Y. Long, and Y. D. Lu, "Study on multistage nonlinear dual mass flywheel damper," Journal of Vibration and Shock, vol. 28, no. 5, pp. 92-96, 2009.

[21] L. P. He, C. G. Xia, S. D. Chen, J. W. Guo, and Y. Liu, "Parametric investigation of dual-mass flywheel based on driveline start-up torsional vibration control," Shock and Vibration, vol. 2019, Article ID 3171698, 2019.

[22] W. B. Ren, Y. H. Chen, G. F. Zhai, and J. Dai, "Research on non-linear vibration characteristics of contact system for switching electrical apparatus used in aerospace," Journal of Vibration and Shock, vol. 26, no. 12, pp. 154-156, 2007.

[23] E. Corral, R. G. Moreno, M. J. G. García, and C. Castejón, "Nonlinear phenomena of contact in multibody systems dynamics: a review," Nonlinear Dynamics, vol. 104, no. 2, pp. 1269-1295, 2021.

[24] P. Põdra and S. Andersson, "Wear simulation with the Winkler surface model,” Wear, vol. 207, pp. 79-85, 1997.

[25] A. Zhu, S. He, J. Zhao, and W. Luo, "A nonlinear contact pressure distribution model for wear calculation of planar revolute joint with clearance," Nonlinear Dynamics, vol. 88, no. 1, pp. 315-328, 2017.

[26] Y. W. Su, W. Chen, and C. X. Guo, "Wear prediction of clearance revolute joints using Winkler model," Mocaxue Xuebao/Tribology, vol. 32, no. 4, pp. 320-324, 2012.

[27] S. Mukras, H. Kim, A. Mauntler, T. L. Schmitz, and G. Sawyer, "Analysis of planar multibody systems with revolute joint wear," Wear, vol. 268, no. 5, pp. 643-652, 2010.

[28] L. Q. Song, H. E. Niu, L. P. Zeng, and H. Tian, "A study on the modeling and torsional vibration attenuation for vehicle powertrain system based on unit analysis," Automotive Engineering, vol. 37, no. 8, pp. 866-874, 2015.

[29] C. Duan and R. Singh, "Transient responses of a 2-dof torsional system with nonlinear dry friction under a harmonically varying normal load," Journal of Sound and Vibration, vol. 285, no. 4-5, pp. 1223-1234, 2005.

[30] A. R. Crowther and N. Zhang, "Torsional finite elements and nonlinear numerical modelling in vehicle powertrain dynamics," Journal of Sound and Vibration, vol. 284, no. 3-5, pp. 825-849, 2005.

[31] Y. S. Chen, Nonlinear Vibration, Higher Education Press, Beijing, China, 2002. 